Sharif University of Technology
Scientia Iranica
Transactions E: Industrial Engineering
http://scientiairanica.sharif.edu

\title{
A hybrid metaheuristic algorithm for data driven leagile sustainable closed-loop supply chain modeling under disruption risk
}

\author{
S. Aghamohamadi-Bosjin ${ }^{\mathrm{a}}$, M. Rabbani ${ }^{\mathrm{a}, *}$, and N. Manavizadeh ${ }^{\mathrm{b}}$ \\ a. School of Industrial Engineering, College of Engineering, University of Tehran, Tehran, Iran. \\ b. Department of Industrial Engineering, Khatam University, Tehran, Iran. \\ Received 5 July 2019; received in revised form 27 June 2020; accepted 14 September 2020
}

\author{
KEYWORDS \\ Leagility; \\ Sustainable supply \\ chain; \\ Disruption risks; \\ Data mining; \\ Multi-objective \\ optimization.
}

\begin{abstract}
In today's world, production and distribution of products in supply chain systems should be done with careful consideration of the environmental and social issues as global concerns about the emission of greenhouse gases within the manufacturing processes and overlooking the major needs of the public are rising. In this regard, the present paper proposes a new multi-objective model for the Closed-Loop Supply Chain (CLSC) problems by incorporating lot sizing and considering lean, agility, and sustainability factors, simultaneously. Furthermore, a robust possibilistic programming approach was applied for handling the uncertainty of the model. To increase the responsiveness of the system, a Fuzzy C-means Clustering Method (FCCM) was employed in order to select the potential locations based on the proximity to local customers. A new hybrid metaheuristic algorithm was developed in order to improve efficiency of the model in dealing with large-size problems and assess the impact of using a single-based initial solution as the income for the second phase of the proposed hybrid algorithm. In addition, to ensure effectiveness of the proposed algorithm, another well-known metaheuristic algorithm was developed. The results achieved by experiments on different test problems approved the superiority of the hybrid metaheuristic algorithm in achieving proper solutions.
\end{abstract}

(C) 2022 Sharif University of Technology. All rights reserved.

\section{Introduction}

In the current competitive atmosphere, many companies are dealing with different economic, environmental, and social concerns. In addition, governments are faced with a large number of restrictions and obligations in limiting the activities of companies and monitoring them. With this in mind, designing Closed-

\footnotetext{
*. Corresponding author. Tel.: +982188021067; Fax: +982188013102

E-mail address: mrabani@ut.ac.ir (M. Rabbani)
}

Loop Supply Chains (CLSC) can be among the useful strategies for both the governments and companies to achieve higher profits alongside considering social benefits. Setting a balance among the economic, environmental, and social considerations in a system is the main goal of sustainable manufacturing. In considering the environmental factors as an important aspect of a sustainable system, transportation networks and production play a vital role. With regard to the economic aspect of a system, besides designing an agile manufacturing strategy, a supply chain should consider expectations of customers and implement a quick-response system to meet the demands as soon as possible. The most optimal employment of re- 
sources and elimination of the useless activities are the fundamentals of lean production. In this regard, incorporating strategic and operational decisions can improve the capabilities of Supply Chain Network Design (SCND) in a competitive atmosphere for more efficient management of systems. In a CLSC, determining the best set of routes between the destinations can reduce the traveling costs and times. Productioninventory management is another important issue in the CLSC, which helps reduce the production costs by setting the number of production batches and number of items to be preserved for the next periods.

Taking into consideration the growing public concern about the current environmental and social issues, many companies are faced with simultaneously contradicting goals, which pose difficulties for Decision Makers (DMs) in making optimal decisions. In this regard, Dehghanian and Mansour [1] designed a network supply chain system and considered the negative environmental effects of the process. They employed different measures, including life-cycle assessment, to evaluate the environmental and social effects of the production process. In addition, Sahebjamnia et al. [2] developed a sustainable closed-loop system for tire industry and incorporated the environmental and social aspects in different stages of the supply chain system, including transportation and facility opening. To reinforce the concept of sustainability and improve the performance of companies while obliging to the environmental restrictions, the proposed model in the present study aims to set a balance among the concepts of agility, leanness, and sustainability. In this respect, considering the major policies for leanness and agility in the strategic and operational decisions of a supply chain can have a significant effect on the sustainability of a system. Therefore, the current study aims to assess the behavior of a model by considering the aforementioned three concepts in a supply chain system and incorporate leanness and agility strategies in order to pave the way for having a sustainable system.

Furthermore, natural and man-made calamities can cause considerable damage to a supply chain and threat the continuity of a business. In this regard, several strategies have been developed to reduce the possible damages of disasters and prepare supply chain systems against unwanted events. These strategies can be categorized into two main groups of operational decisions and strategic decisions. The operational decisions occur instantly after a disruption begins. The strategic decisions take place before the occurrence of a disruption to fortify an SCND against disruption. In this regard, business continuity planning is a useful management tool to provide a framework and identify the internal and external factors affecting a supply chain under disruption (ISO 22301, 2012).

In this paper, we consider lean, agile, and sus- tainable manufacturing strategies simultaneously for a CLSC problem in which strategic and tactical decisions are integrated. In addition, strategic and operational decisions are made to face disruption risks. The main contributions of this study are the following:

- Designing a new sustainable CLSC problem under partial facility disruption considering locationallocation, lot sizing, shortage, and routing decisions, simultaneously;

- Applying an $\mathrm{M} / \mathrm{M} / \mathrm{c}$ queue system in order to reduce the congestion in a system, shipment time, and related costs by taking into consideration the alternative routes;

- Applying strategic and operational decisions in order to increase the resiliency of a system against disruptions;

- Desigining a data-driven model through the Fuzzy C-means Clustering Method (FCCM) to select and rank the best possible locations as the nominated locations for Production Centers (PDCs) and Reproduction Center (RCs);

- Employing a new hybrid metaheuristic algorithm to efficiently solve the problem;

- Considering the major concepts of agility, leanness, and sustainability to design a new supply chain model;

- Implementation of the presented model for a real case.

The rest of the paper is organized as follows: The relevant literature is reviewed in Section 2. Section 3 introduces the model, and the method to deal with uncertainty of the model is explained in Section 4. In Section 5, the major solution method is presented the results of which are given in Section 6. Finally, Section 7 concludes the paper.

\section{Literature review}

In this section, a review of CLSCs in the literature is presented. Generally, research studies in this field have focused on lot sizing, sustainability, disruption risks, and queue systems, as introduced in the following.

\subsection{Location, lot sizing, and routing in a supply chain}

Location, allocation, routing, and inventory decisions are dealt with in various types of supply chain problems [3-5]. Lot sizing has been considered in some studies of CLSC besides other strategic and tactical decisions for system. Pan et al. [6] studied a lot sizing problem in CLSC by disregarding the returned products and adopted a dynamic programming algorithm to handle the problem. Soleimani and Kannan [7] stated 
that CLSC was an NP-hard problem. They designed an integrated CLSC problem consisting of location, inventory, and shipment decisions and used a hybrid metaheuristic algorithm to solve the problem in hand. Kannan et al. [8] formulated a model for the CLSC problem by taking into account the production, shipping, reproduction, and recycling decisions in the structure of their model and implemented it in the battery industry as a real case. They used a genetic algorithm to solve the problem. Torkaman et al. [9] compared the performance of a Simulated Annealing (SA) algorithm with a heuristic approach in solving a multi-product production planning problem with sequence-dependent set up times in a CLSC and showed the superiority of $\mathrm{SA}$ for solving large-size instances. $\mathrm{As}^{\prime}$ ad et al. [10] developed a CLSC problem in which raw material procurement, transportation, and lot sizing decisions were integrated. They assumed two different strategies for the provision of raw material and applied an iterative search algorithm in order to solve the problem. Hasanov et al. [11] proposed a four-level CLSC problem by determining the order quantities and inventory level of the system and assumed that a part of the demand was met from the remanufactured items. They proved that higher remanufacturing rates would lead to lower manufacturing costs. Hajiaghaei-Keshteli and Fathollahi-Fard [12] developed a novel mixed-integer CLSC model and included discount supposition in the shipment expenditures. They used different hybrid metaheuristic algorithms and compared the results for the aforementioned model. Taleizadeh et al. [13] developed a multi-objective CLSC model for the light-bulb industry and used the global reporting initiative indicators for the environmental and social factors. Taking into account the pricing and discounting decisions in the tactical decision making for a logistic system was one of the major features of their study. They used the Torabi-Hassini method to deal with the multi-objective model. Safaeian et al. [14] proposed a multi-objective model for a supply chain network problem to determine the suppliers and allocate the orders. They used a multi-objective metaheuristic method in order to solve the problem. Fathollahi-Fard et al. [15] formulated the logistic system for a home health care problem considering the environmental aspects besides the costs of the system. They used different simulated annealing algorithms to solve the problem. In addition, Feng Zhang et al. [16] used Multi-Criteria Decision-Making (MCDM) methods for the supplier selection problem in a collaborative manufacturing enterprise. Liu et al. [17] developed new hybrid MCDM methods to appraise the environmental aspects of the manufacturing process for ships. There are different types of metaheuristic algorithms to deal with supply chain problems. Fathollahi-Fard et al. [18] showed the highly superior performance of hybrid metaheuristics in dealing with large-size supply chain problems. In addition, there are other articles employing hybrid metaheuristics and multi-objective metaheuristics to solve manufacturing and supply chain problems $[19,20]$. Fathollahi-Fard et al. [21] introduced a two-stage stochastic model for the water supply and applied a Lagrangian relaxationbased algorithm in order to solve the problem.

\subsection{Leanness, agility, sustainability, and disruption risk in a supply chain}

Fahimnia et al. [22] assessed the effect of greenhouse gas pricing on the forward and backward flows of a CLSC and used a case study to show the applicability of their model. Govindan et al. [23] included environmental issues in all of the supply chain parts besides economic factors and used a hybrid approach to dealing with the multi-objective problem. Mokhtari and Hasani [24] proposed a supply chain model with two objective functions. Their model determined production and inventory level, transportation mode, and back-order level. They employed a fuzzy goal programming method to reduce the related costs and environmental effects of the system, concurrently. Chalmardi and Camacho-Vallejo [25] developed an SCND problem and considered the social and environmental aspects alongside economic objectives in the problem. In their proposed model, the government played the role of the leader and the manager of the company was the follower. They adopted an algorithm based on Simulation Annealing (SA) to solve the problem in hand.

Risk management is one of the main factors of an agile production system that enhances responsiveness by incorporating immunity of the system [26]. In this area, multiple-sourcing is one of the prevalent strategies for facing disasters. In multiple-sourcing, each retailor can be assigned to more than one node [27]. Mohammaddust et al. [28] designed a lean and responsive nonlinear model for a supply chain problem and considered different types of backup strategies to face the risk of a system. They applied a regression approximation method to linearize the model. Rohaninejad et al. [29] studied a multi-echelon SCND with unreliable facilities and assumed the facilities could be "hardened." They used different approximation algorithms to solve largesize problems.

\subsection{Queue system and uncertainty in supply chain}

Considering the overcrowding caused by the differences between the processing rate of the servers and the arrival rate of the incoming flow in facilities, queuing approach can be a useful tool to reduce congestion in a system as a lean strategy. Ghobadi et al. [30] highlighted the importance of the queue system in reducing the service time and enhancing customer sat- 
isfaction. Vahdani et al. [31] applied the queue system for a bi-objective supply chain problem, incorporating total costs and unforeseen transportation costs, and used a Robust Optimization (RO) approach in order to confront the uncertain parameters. Saeedi et al. [32] developed an uncertain model for an CLSC problem and tried to set a balance between queue costs and other costs of the system to determine the capacity of facilities. Vahdani and Mohammadi [33] formulated an uncertain supply chain problem and used a queue system to decrease the processing time.

Stochastic programming is a prevalent method to deal with uncertain parameters when experts know the distribution of random data. However, in the absence of enough data to guess the probable distribution of parameters, RO is a suitable approach enabling DMs to obtain reliable solutions [34]. Sadghiani et al. [35] proposed a retail SCND model with operational and disruption risks and employed a possibilistic-robust method to handle the vagueness of parameters. Kim et al. [36] used a robust method to deal with uncertain product recycling and customer demand for a CLSC and showed the efficiency of their method in dealing with uncertainty. Hajipour et al. [37] proposed a CLSC problem by incorporating radio frequency identification in order to reduce the lead time and meet social and environmental objective functions, simultaneously. To handle the uncertainty of the model, they applied stochastic programming.

\subsection{Contributions of the current study}

Referring to the previous section and taking a look at Table 1, it becomes clear that there are a large number of studies that consider strategic (facility establishment) and tactical (inventory, lot sizing, reproduction, and routing) decisions in the structure of their proposed models. However, few researches have considered all the aforementioned decisions simultaneously to enhance the integrity and applicability of their models. Moreover, while taking into consideration the pillars of lean and agile production can make considerable positive effects on the environmental, social, and economic aspects of the manufacturing systems, few studies have proposed mathematical analyses to set a balance among the aforementioned dimensions. Applying queue systems and shortages are other directions that can have considerable effects on a system. Finally, there are few studies paying attention to the disruption effects on the environmental, social, and economic aspects of a lean/agile supply chain system. In general, it can be claimed that there are some gaps in the context of CLSC, as described in the following, which will be dealt with in one way or another by the model proposed in the present research:

- The integration of location-allocation, lot sizing, inventory, and routing decisions in a CLSC problem;

- Considering quick response (and other agility met-

Table 1. Summary of the related studies.

\begin{tabular}{|c|c|c|c|c|c|c|c|c|c|c|c|c|c|c|}
\hline \multirow[b]{2}{*}{ Ref. } & \multicolumn{6}{|c|}{ Decisions } & \multicolumn{5}{|c|}{ Features } & \multicolumn{2}{|c|}{$\begin{array}{c}\text { Disruption } \\
\text { risks }\end{array}$} & \multirow[b]{2}{*}{ Uncertainty } \\
\hline & 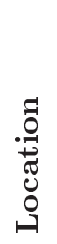 & 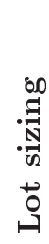 & 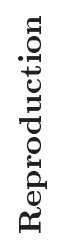 & $\begin{array}{l}\overrightarrow{0} \\
0 \\
\stackrel{0}{ \pm} \\
\overrightarrow{0} \\
\vec{\Xi}\end{array}$ & تص & 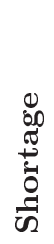 & 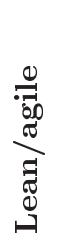 & 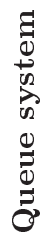 & 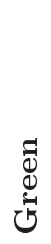 & 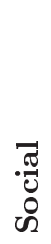 & 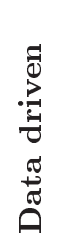 & 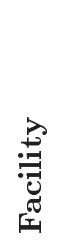 & $\begin{array}{l}\stackrel{0}{\leftrightarrows} \\
\stackrel{0}{0}\end{array}$ & \\
\hline [6] & & $*$ & $*$ & & & & & & & & & & & \\
\hline$[7]$ & $*$ & & & $*$ & & & & & & & & & & \\
\hline [8] & & & $*$ & $*$ & & & & & & & & & & \\
\hline [9] & & $*$ & $*$ & & & & & & & & & & & \\
\hline$[10]$ & & $*$ & & * & & & & & & & & & & \\
\hline [13] & $*$ & & & & $*$ & & & & $*$ & $*$ & & & & $*$ \\
\hline$[15]$ & $*$ & & & & $*$ & & & & $*$ & & & & & \\
\hline [23] & & $*$ & $*$ & $*$ & & $*$ & & & $*$ & & & & & \\
\hline$[24]$ & $*$ & & & $*$ & $*$ & & & & $*$ & & & & & \\
\hline$[25]$ & & & & $*$ & $*$ & $*$ & & & $*$ & & & & & \\
\hline$[26]$ & $*$ & & & $*$ & $*$ & & & & * & $*$ & & & & \\
\hline$[28]$ & $*$ & & & & $*$ & & & & & & & $*$ & & \\
\hline$[37]$ & $*$ & & $*$ & & $*$ & & & & $*$ & $*$ & & & & $*$ \\
\hline This study & $*$ & $*$ & $*$ & $*$ & $*$ & $*$ & $*$ & $*$ & $*$ & $*$ & $*$ & $*$ & $*$ & $*$ \\
\hline
\end{tabular}


rics) to increase the responsiveness of a CLSC problem;

- Considering lean and agile production strategies to support the social and environmental objectives of a CLSC problem;

- Considering the concurrent disruption of facilities and routes in a CLSC problem;

- Considering backup storage, backup supplier, multiallocation, and alternative route decisions as the operational and strategic decisions to increase resiliency of a system against partial disruption risks;

- Considering storage and service level constraints in a CLSC problem under partial disruption risks;

- Proposing a data-driven modeling to increase the agility level of a manufacturing system.

In the next section, we propose a new multi objective model that covers all the aforementioned research gaps. Table 1 gives a summary of the literature reviewed.

\section{Problem description}

\subsection{Modeling framework}

In most of the CLSC problems with location-allocation decision, the potential locations are predetermined, while in real situation, the candidate nodes should be determined based on the discretion of the DMs. Thus, we developed a data-driven modelling in which the candidate nodes were identified based on proximity to local clients in order to increase the service level and agility of the SC system. In the proposed CLSC problem, the suppliers sent the required items through PDCs to the retailers. The retailers were responsible for collecting and sending the returned products to RCs. The route for the vehicle began from a PDC and after visiting the retailers, it returned to its departing PDC. The scrapped items were sent back to the retailers, after remanufacturing process in the RCs. PDCs received their required materials from suppliers based on their dollar value. The strategic and operational decisions of the model to reduce the damages of the disasters included: satisfying the demand of retailors through more than one PDC/RC (multi-allocation), assigning more than one supplier to PDCs, assigning backup stores to PDCs/RCs, and applying an $\mathrm{M} / \mathrm{M} / \mathrm{c}$ queue system in order to reduce the waiting time of machines in routes due to disruption effects, which could be considered as a quick-response strategy derived from the agile manufacturing concept. The main assumptions in the design of the novel CLCS model are the following:

- The positions of the supplier and retailers are known;

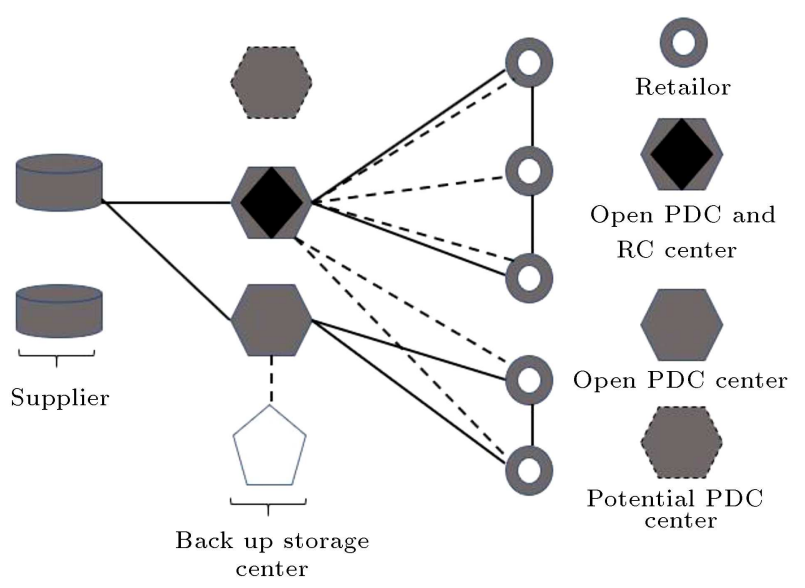

Figure 1. The structure of the proposed CLSC network.

- RCs can only be established at locations where PDCs are open;

- Reproduced items have the same quality as the new produced items;

- Opening a PDC or RC in a region results in potential risks due to facility disruptions;

- Vehicles spend more time on some routes because of traffic caused by disruptions.

Figure 1 (based on Ramezani et al. [38]) demonstrates the structure of the proposed model. The notation used in the model is given in Appendix A.

\section{2. $M / M / c$ queuing system}

In this section, a queue system is designed in order to reduce the driver and depreciation cost of trucks due to waiting time in the PDCs/RCs (i.e. loading and unloading) and routes (i.e., route disruption). Here, the incoming flow of vehicles is varied and a Poisson distribution is used to calculate their waiting time in RCs. The notation used in the model is introduced in Appendix B.

The required time for vehicles to receive service in an $\mathrm{RC} / \mathrm{PDC}$ center is calculated by:

$$
\begin{aligned}
& W T_{r / i}^{t}=\left(\lambda_{r / i} / \mu_{r / i}\right)^{\vartheta_{r / i}} \mu_{r / i} /\left(\vartheta_{r / i}-1\right) ! \mu_{r / i} \vartheta_{r / i} \\
& \left.-\lambda_{r / i}\right)^{(2)}\left[1+\sum_{n=0}^{\vartheta_{r / i}-1} 1 / n !\left(\lambda_{r / i} / \mu_{r / i}\right)^{n}\right. \\
& \left.+1 /\left(\vartheta_{r / i} !\right)\left(\lambda_{r / i} / \mu_{r / i}\right)^{n}\left(\lambda_{r / i} /\left(\lambda_{r / i}-\mu_{r / i}\right)\right)\right]^{-1},
\end{aligned}
$$

where the arrival rate $\lambda_{r / i}$ in the CLSC is calculated by:

$$
\lambda_{r / i}=\sum_{w} N u m_{w r / i}^{t}
$$

Finally, the Total Waiting Cost (TWC) is calculated by: 


$$
\begin{aligned}
T W C= & \left(\sum_{t} \sum_{p} \sum_{w} \sum_{i}\left(\text { Spe } / d i s_{w i}+W T_{i}^{t}\right)\right. \\
& \varphi_{3} N_{u m}^{t}{ }_{w i} A X_{w i} \\
& +\sum_{t} \sum_{p} \sum_{w} \sum_{r}\left(S p e / d i s_{w r}+W T_{r}^{t}\right) \\
& \left.\varphi_{3} N_{u m}^{t} B X_{w r}\right) V c p t .
\end{aligned}
$$

As per Eq. (3), the model decides to assign an appropriate $\mathrm{PDC} / \mathrm{RC}$ center to a retailer with the lowest waiting time in the routes and PDCs/RCs. In other word, assigning multiple $\mathrm{PDCs} / \mathrm{RCs}$ to retailors enables the model to assess the shipment time of alternative routes.

\subsection{Mathematical programming}

The following section shows the proposed MultiObjective Mixed-Integer Non-Linear Problem (MOMINLP). It should be noted that Eqs. (3), (5), (8), (16)-(18), and (35)-(36) as well as constraints (19)-(20), (30), and (33)-(34) are the foundations of the model.

$$
\begin{aligned}
a_{1}= & \sum_{i} P o_{h i} C P D C_{i}+\sum_{r} R o_{h r} C R C_{r} \\
& +\sum_{t} \sum_{p} \sum_{i} b_{p i t} b o c s_{p t}+\sum_{r} X r c_{r} F r c_{r} \\
& +\sum_{i} X p d c_{i} F p d c_{i} \sum_{t} \sum_{p} \sum_{s} \sum_{i} \sum_{w}\left(P R C_{p r} X_{p i t}\right. \\
& \left.+ \text { Inv } p_{p i t} I n c_{p i}\right) R X_{s i} a X_{w i}+\sum_{s} \sum_{p} \sum_{i} F S_{p s i} R X_{s i} \\
& +\sum_{t} \sum_{p} \sum_{i} \sum_{s} R X_{s i} U S_{s i p} x_{p s i t}^{0} \\
& \sum_{t} \sum_{p} \sum_{s} \sum_{i} \sum_{w} \sum_{r} U S_{r s p} x_{p i r t}^{1} R X_{s r} B X_{w r} \\
& +\sum_{t} \sum_{p} \sum_{s} \sum_{i} \sum_{w} \sum_{r} R c p_{p r} x_{p i r t}^{1} R z_{s r} B X_{w r} \\
& \sum_{t} \sum_{a} \sum_{b} \sum_{v} D i s c_{a b} R o u t_{a b v}^{t} \\
& +\sum_{t} \sum_{a} \sum_{b} \sum_{v} M a c o_{v} R o u t_{a b v}^{t} \\
& +\sum_{t} \sum_{i} \sum_{s} \sum_{p} b s p c_{p} R o u t_{a b v}^{t} \hat{x}_{p s^{\prime} i t}^{0} .
\end{aligned}
$$

Eq. (4) calculates the opening costs of PDCs and RCs; the shortage cost; the renting cost of backup store; the production and inventory costs of PDCs by considering the network connection between PDCs; the fix ordering cost of raw materials from suppliers; the shipment cost of items to the retailers; the shipment cost of scraped items from retailors to RCs; the reproduction cost of the scraped items by regarding the network connection among RCs, retailers, and suppliers; the shipment cost between nodes; the fixed cost of vehicles usage; and the cost of contracting with other backup suppliers.

$$
a_{2}=\sum_{t} \sum_{v} \sum_{i} \sum_{w}\left(M_{c a p} L A O_{i w v}^{t}\right) C c p u_{v} .
$$

Eq. (5) minimizes the unused capacity of vehicles during the transportation of items and its related costs. The optimal utilization of truck carrying capacity reduces the number of round trips to meet the demand of clients. This equation reduces the number of non-added value activities, which can be taken into consideration as a lean routing strategy.

$$
\min z_{1}=a_{1}+a_{2}+T W C \text {. }
$$

Finally, Eq. (6) calculates the first objective function in which the items were described in the previous sections.

$$
\begin{aligned}
\min z_{2}= & \sum_{t} \sum_{p} \sum_{i} \operatorname{Pemi}_{p i} X_{p i t} \\
& +\sum_{t} \sum_{p} \sum_{r} R P e m i_{p i} x_{p i r t}^{1} \\
& +\sum_{t} \sum_{a} \sum_{b} \sum_{v} \operatorname{Disc}_{a b} \text { Remi }_{v}\left(a c c_{v}\right. \\
& \left.+\sin (a, b)+g \cos (a, b) a c c_{v} \text { rol }\right) \text { Ewe }_{v} \text { Rout }_{a b v}^{t} .
\end{aligned}
$$

Eq. (7) depicts the second objective function, which deals with the environmental effects of $\mathrm{CO}_{2}$ emissions, including production, reproduction, and transportation effects. It should be noted that the third part of Eq. (7) calculates the environmental effects of transportation not only based on the traveled distance, but also based on the cargo weight and rolling resistance of the road.

$$
\min z_{3}=\sum_{i} P o_{i m} N P I_{i} \varphi_{1}+\sum_{r} R o_{r m} N P I_{r} \varphi_{2}
$$

Eq. (8) shows the third objective function. This objective function minimizes the negative social impacts of establishing production/reproduction centers and aims to reduce the risk of facility disruptions. In the following, the constraints of the model are demonstrated and described:

$$
\sum_{s} R x_{s i}=P o_{h i} \quad \forall i, h,
$$




$$
\begin{aligned}
& \sum_{s} R z_{s r}=R o_{h r} \\
& \forall r, h, \\
& P o_{h i} \leq R o_{h r}, \\
& \forall r, h, i, \\
& \sum_{i} P o_{h i} \leq 1, \\
& \forall h \text {, } \\
& \sum_{r} R o_{h r} \leq 1, \\
& \forall h, \\
& \sum_{h} P_{o_{h i}} \leq 1, \\
& \forall i, \\
& \sum_{h} R o_{h r} \leq 1, \\
& \forall r, \\
& I n v_{p i t}+d e m_{p}^{t}-\operatorname{Inv}_{p i t-1}-x_{p i r t-1}^{1}+b_{p i t-1} \\
& =X_{\text {pit }}+b_{\text {pit }} \\
& \forall p, i, t, \\
& x_{p i r t-1}^{1} B X_{w r}=X_{p i t} A X_{w i} \varphi_{1 p} \\
& \forall p, i, t, \\
& x_{p s i t}^{0} R X_{s r}+\hat{x}_{p s^{\prime} i t}^{0} E x s_{p t}=X_{p i t} \varphi_{0 p} \\
& \forall p, i, t, \\
& \sum_{p} \operatorname{Inv}_{p i t} A X_{w i} V U N_{p} \leq \operatorname{Icap}_{i} p 2_{i} p o_{h i} \\
& \forall w, i, t, \\
& \sum_{w} \sum_{i} \sum_{p} \operatorname{Inv}_{p i t} B X_{w r} V U N_{1 p} \leq \operatorname{Icap}_{r} p 3_{r} R o_{h r} \\
& \forall r, t, \\
& \sum_{a} \sum_{b} R_{b u t}^{t}{ }_{a b v}=1 \\
& \forall v, t, \\
& \sum_{w} d e m_{p w}^{t} A X_{w i} \leq X_{p i t} \\
& \forall p, t, i, \\
& M_{w v t}-M_{w u t}+N R E+R_{o u t}^{t}{ }_{w u v} \leq N R E-1 \\
& \forall w, u, t, \\
& \sum_{b} R_{0 u t}^{t}{ }_{a b v}=\sum_{a} R_{0 u t}^{t} t_{b a v} \\
& \sum_{i} \sum_{w} \operatorname{Rout}_{a b v}^{t} \leq 1 \\
& \forall v, t \\
& \sum_{u} \text { Rout }_{w u v}^{t}+\sum_{u} \text { Rout }_{\text {iuv }}^{t}-A X_{w i} \leq 1 \\
& \forall v, t, i \\
& 1 \leq \sum_{i} A X_{i w} \\
& \forall w, \\
& 1 \leq \sum_{r} B X_{w r} \\
& \forall w,
\end{aligned}
$$

$$
\operatorname{Rout}_{i j v=0}^{t} \quad \forall i, j, t, v,
$$$$
\sum_{w} \sum_{u} L A O_{w u v}^{t}-\sum_{p} D e m_{p u}^{t}=\sum_{w} \sum_{v} L A O_{u w v}^{t}
$$$$
\forall u, v, t
$$

$$
L A O_{\text {wuv }}^{t} \leq \text { Rout }_{w u v}^{t} B N \quad \forall u, w, t,
$$$$
\sum_{p} \sum_{u} \text { Dem }_{p u}^{t} \text { Rout }_{w u v}^{t} \leq \sum_{u}\left(1-\text { Rout }_{\text {wuv }}^{t}\right) B N
$$$$
+L A O_{w u v}^{t} \leq \operatorname{Mcap}_{v}\left(1-\operatorname{Rout}_{w u v}^{t}\right) B N
$$

$\forall p, v, t$,

$$
\left(\sum_{p} X_{p i t} / M c a p_{v}\right) \leq N u m_{w r / i}^{t} \quad \forall i, v, t,
$$

$$
\left(\sum_{i} b_{p i t} / \operatorname{Dem}_{p u}^{t}\right) W o c_{p} \leq 1-a s \quad \forall p, t,
$$

$$
\begin{aligned}
& I c a p_{i}=\operatorname{Icap}_{i}\left(1-X p d c_{i}\right)+\left(I c a p_{i}+s s\right)\left(X p d c_{i}\right) \\
& \forall i, \\
& I c a p_{r}=I c a p_{r}\left(1-X r c_{r}\right)+\left(I c a p_{r}+s s\right)\left(X r c_{r}\right) \\
& \forall r .
\end{aligned}
$$

Eqs. (9) and (10) indicate that each open PDC and RC must be assigned to one supplier. Constraint (11) ensures that an RC can be established where a PDC is open. Eqs. (12) and (13) guarantee that at most one of the PDC and RC centers can be established in a candidate place. Eqs. (14) and (15) imply that at most one candidate place must be assigned to a PDC and RC, respectively. Eq. (16) shows the productioninventory balance constraint of the products. In this equation, some orders that cannot be satisfied on time are allowed to be backlogged. Eqs. (17) and (18) calculate the amounts of raw material and reproduction items by considering the relations among each supplier, PDC, and retailer as a network system. Eq. (18) demonstrates that a PDC is able to receive its raw material through the main supplier or the backup supplier. Constraints (19) and (20) are associated with the capacity of storage in PDCs and RCs. In the both equations, the capacity of the centers may change due to disruption. Eq. (21) indicates that every route is assigned to a vehicle. Constraint (22) shows the minimum amount of production for a PDC to meet the demand of a retailer. Constraint (23) removes the sub-tours and ensures that each route is comprised of one PDC and some retailor. Eq. (24) 
is associated with flow protection and indicates that when a vehicle visits a place, it should leave that place within an equal time period. Constraint (25) states that a maximum PDC can exist in a route. Constraint (26) describes that a retailor should be allotted to a PDC if there is a connection between them by the vehicle. Eqs. (27) and (28) indicate that at least one PDC and $\mathrm{RC}$ can be connected to a retailer. These equations show the multi-allocation nature of the problem, which improves the resiliency and leanness of the system by increasing the routing options. In other word, designing a routing problem with various decisions can reduce the number of trips and provide a wider area of routing. Eq. (29) ensures that there is no route between PDCs. Eq. (30) indicates that the load of a vehicle varies by visiting a retailor on its route. Constraint (31) describes that the load of a vehicle remains constant when the vehicle does not meet the retailer $u$. Constraint (32) shows the minimum and maximum limitations of loads for a vehicle to visit the retailors. Constraint (33) determines how many vehicles are needed to ship the returned items from retailor $(w)$ to $\mathrm{RC}(r)$. Constraint (34) is about the service level of the system by determining the percentage of orders that are not satisfied. Eqs. (35) and (36) calculate the capacity of PDCs and RCs by taking into consideration the backup storage decisions.

\section{The robust possibilistic approach}

Considering the uncertain and instable nature of some parameters, on the one hand, and the lack of historical data, on the other hand, such parameters are set based on experts' judgment as trapezoidal fuzzy numbers. Here, a Possibilistic Chance-Constrained Programming (PCCP) is developed to handle the uncertain constraints. The DM is able to determine the lowest degree of confidence for uncertain constraints as a safety margin to satisfy each uncertain constraint. Next, possibility (Pos) and necessity (Nec) are utilized as fuzzy measures. In this regard, the possibility measure specifies the optimistic possibility related with an uncertain event and the necessity measure demonstrates the lowest possible value for an uncertain parameter according to the attitude of the DM. It is a risk averse strategy to use the necessity measure by considering the DM opinion. This approach considers the minimum confidence level, which can be changed based on the DM's preferences, and helps develop a model that is efficient against changes of uncertain parameters. Also, resilient strategies are added to the model to increase the reliability of the system.

\section{Proposed solution approach}

The solution approach to the problem includes two main steps. At the first step, an FCCM is employed in order to determine the potential centers to locate PDCs/RCs based on proximity to the local customers. In the second phase, the results of the previous step are imported into the model proposed in Section 3.3. The presented model is NP-hard since it is comprised of location, lot sizing, and vehicle routing as NP-hard problems $[39,40]$. In addition, considering different conflicting objective functions and proposing a robust possibilistic approach to dealing with the uncertainty of the model are the other reasons intensifying the complexity of the model. Thus, a multi-objective metaheuristic algorithm is used to solve the model.

\subsection{Fuzzy C-means Clustering Method ( $F C C M$ )}

In this section, the locations of local customers are categorized into clusters by utilizing the FCCM. In this study, we desire to partition $u$ customer locations into $i$ clusters. Also, let $x_{u}$ be the vector related to the location of customer $u$.

\subsection{Solution representation}

An appropriate solution representation covers all of the potential solutions so as to make the best choice available. Considering the structure of the model, an order-based solution representation could be a good approach to assessing the candidate solutions. In the proposed order-based encoding structure, each chromosome is designed based on the order of the components of the model. In this regard, a smallsize problem (i.e., $|h| \times|s| \times|i| \times|r| \times|w| \times|p| \times$ $|v| \times|t|=5 \times 2 \times 4 \times 2 \times 6 \times 2 \times 3 \times 2)$ is proposed to introduce the solution representation. As depicted in Figure 2, in the structure of the proposed solution, the first chromosome is a $(|1| \times|h|)$ matrix determining the centers to establish PDCs by selecting potential locations, randomly. In the first $r$ cells of this chromosome, RCs are allowed to be established. The second and third chromosomes are $(|s| \times|i|)$ and $(|s| \times|r|)$ matrices related to the connections among the suppliers, PDCs, and RCs, respectively. The fourth and fifth chromosomes are $(|1| \times|i+w+v-1|)$ and $(|1| \times|r+v+w-1|)$ matrices addressing the order of retailers, PDCs, and RCs to be visited by vehicles. In addition, a repair function is designed to alter the generated responses by these chromosomes. The sixth chromosome is a $(|p| \times|t|)$ matrix that calculates the number of produced items during the planning horizon by multiplying the random numbers by the determined production range. The two last chromosomes $(|1| \times|i|)$ and $(|1| \times|r|)$ are related to the allocation of backup storage centers to PDCs and RCs. Other constraints such as production capacity, storage capacity, and service level are regarded by adding penalty function to the main objective functions. 


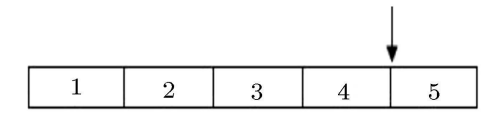

Order of location selection

\begin{tabular}{|l|l|l|l|}
\hline 0 & 1 & 1 & 0 \\
\hline 1 & 0 & 0 & 1 \\
\hline
\end{tabular}

Allocation of PDCs to suppliers

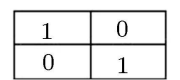

Allocation of RCs to suppliers

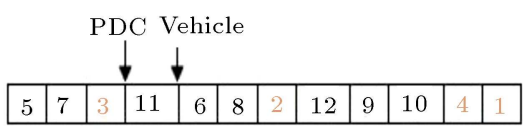

Retailors

Order of vehicle routing between PDCs and retailors

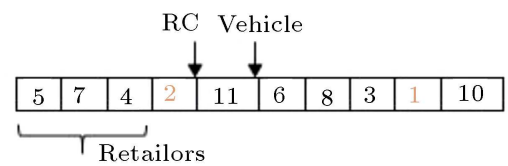

Order of vehicle routing between RCs and retailors

\begin{tabular}{|l|l|}
\hline 0.34 & 0.2 \\
\hline 0.45 & 0.71 \\
\hline
\end{tabular}

Initial lot sizing plan

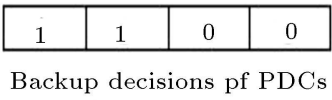

\begin{tabular}{|c|c|}
\hline 1 & 0 \\
\hline
\end{tabular} Backup decisions of RCs

Figure 2. Solution representation.

\subsection{Parallel version of the MOPSO (PMOPSO)}

Multi Objective Particle Swarm Optimization (MOPSO) produces a Pareto-optimal solution set to make a balance between different objectives. A Pareto-optimal solution cannot be conquered or cannot be better without deteriorating at least one other objective. In this study, a master-slave approach is used to change the MOPSO algorithm into a parallelized version. In this method, the fitness evaluations for each particle are processed independently and the algorithm is decomposed to run the evaluations, simultaneously, as a parallel system. $v_{p}(t)$ and $x_{p}(t)$ denote the velocity and the position of each particle, respectively, based on Eqs. (37) and (38):

$$
\begin{aligned}
v_{P}(t)= & w v_{P}(t-1)+c_{1} r_{1}\left(x_{\text {Pbest }-x_{P}}(t)\right) \\
& +c_{2} r_{2}\left(x_{\text {gbest }-} x_{P}(t)\right), \\
x_{P}(t)= & x_{P}(t-1)+v_{P}(t) .
\end{aligned}
$$

\subsection{Social Engineering Optimizer (SEO)}

The Social Engineering Optimizer (SEO) is a new single solution metaheuristic algorithm introduced by
Fathollahi-Fard et al. [41]. Zhang et al. [42] compared the performance of SEO with other metaheuristics in solving the SCND problems. Baliarsingh et al. [43] developed a memetic algorithm-based method in which a SEO algorithm was employed for local search to deal with a medical data classification problem. FathollahiFard et al. [44] proposed a truck scheduling problem and solved the model by using different versions of the SEO through putting different weights on the SEO features. In the SEO algorithm, the solutions are regarded as different persons with various abilities. The SEO algorithm starts by generating two initial solutions and dividing the solutions to attacker and defender. In this regard, the attacker assesses the abilities of the defender to find its efficient traits. There are four approaches to spotting an attack, each described as follows.

\subsubsection{Obtaining}

In this method, the attacker abuses the defender to obtain the desired goal, where $d e f_{\text {new }}$ and $d e f_{\text {old }}$ denote the new and old positions of the defender, respectively, att specifies the current position of the attacker, and $\beta$ is the rate of spotting for an attacker.

$$
d e f_{\text {new }}=d e f_{\text {old }}\left(1-\sin \beta r_{1}\right)+\frac{a t t+d e f_{\text {old }}}{2} \sin \beta r_{2}(20) \text {. }
$$

\subsubsection{Phishing}

In this approach, the position of the attacker is determined based on the following formula:

$$
\operatorname{def}_{\mathrm{new}}=\operatorname{att}\left(1-\sin \beta r_{1}\right)+\frac{a t t+\operatorname{def}_{\text {old }}}{2} \sin \beta r_{2} .
$$

\subsubsection{Diversion theft}

In this method, the attacker guides the defender in a new position in deception.

\subsubsection{Pretext}

In this method, the attacker traps the defender (see [44]).

\subsection{Hybrid PMOPSO G SEO (HPSO-SEO)}

As mentioned in Section 5.4, the SEO is a single solution algorithm with some advantages including short computational time, good intensification phase, and the ability to make a trade-off between the diversification and intensification phases. However, population-based algorithms are also able to find good solutions [41]. Thus, it makes sense to propose a hybrid metaheuristic that benefits from the advantages of a population-based algorithm (PMOPSO) and a single solution algorithm (SEO), simultaneously. In this regard, in the first step of the proposed hybrid algorithm, the PMOPSO, which is able to cover more possible and various solutions in the exploration phase, is implemented to find a good initial solution. Next, the 


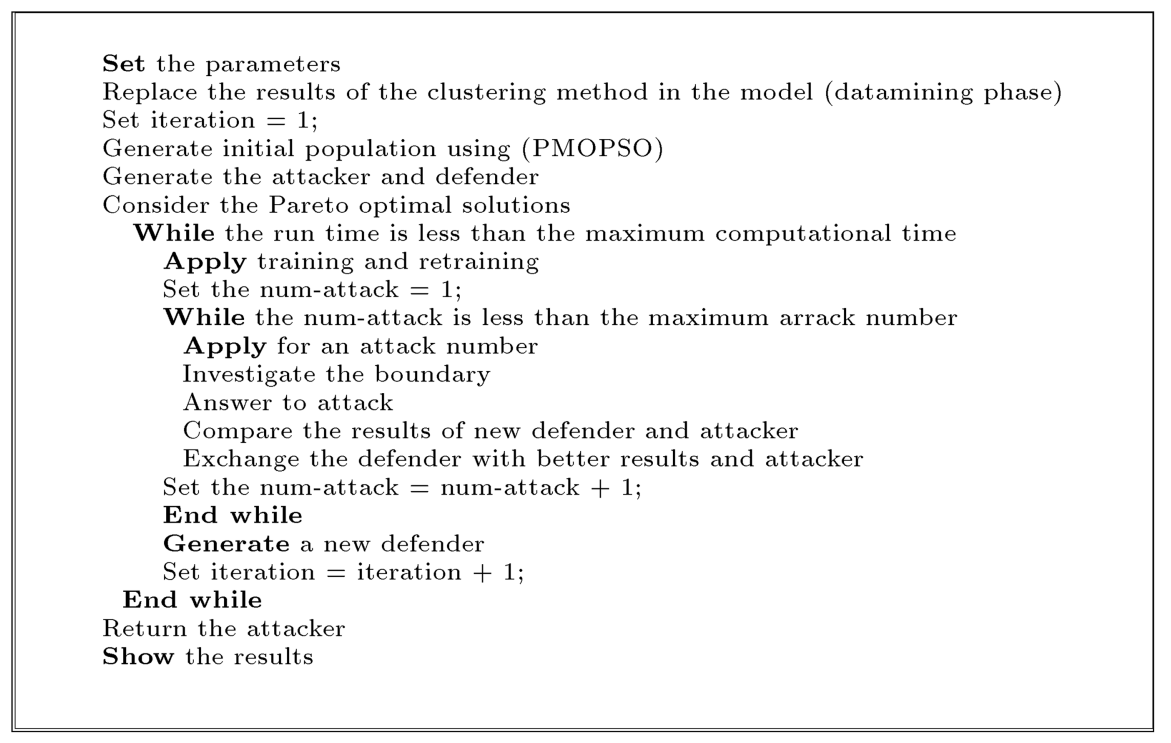

Figure 3. Summary of the HPSO-SEO algorithm.

results achieved by the previous method are imported into the SEO algorithm, which helps improve the results in the exploitation phase. Figure 3 summarizes the HPSO-SEO.

\subsection{NSGA-II}

NSGA-II comprises of generating an initial population, evaluation of members, and sorting the results. This operator selects top-rank individuals with higher probability. NSGA-II uses crossover to generate solutions similar to the initial chromosomes and mutation to generate more diverse solutions.

\section{Results and discussion}

\subsection{Model validation}

In this section, the behavior and feasibility of the model in reaching the optimum values for the objective functions are assessed. In this regard, a small-scale deterministic problem (i.e. $|h| \times|s| \times|i| \times|r| \times|w| \times$ $|p| \times|v| \times|t|=10 \times 2 \times 4 \times 2 \times 6 \times 3 \times 3 \times 10)$ is considered and solved by GAMS applying the Baron solver because of the nonlinear nature of the presented model. Since the proposed model is comprised of multiple objective functions, we divide the main problem into separate sub-problems based on the method and consider each objective function separately along with the constraints. The parameters of the model are determined based on the proposed case of study as reported in Table 2. Table 3 demonstrates the optimal decisions for each sub-problem, separately. For the first sub-problem, the model tends to decrease the costs of the system and decides to consider backup storage decisions due to high costs of establishing other PDC and $\mathrm{RC}$ centers as well as service level constraints. For the second sub-problem, the model decides to include a higher number of tours. As a result, each PDC will cover fewer retailers and each $\mathrm{RC}$ has to remanufacture fewer retailers. Therefore, the number of carried loads and environmental effects will be decreased. For the third sub-problem, establishing PDCs and RCs will increase the disruption risk and hence, the model decides to open one center. Notably, this model does not regard the shipping costs.

\subsection{Tuning of the parameters}

The Taguchi method is an appropriate means for enhancing the performance of metaheuristic algorithms. It should be noted that the basic initial parameters of the SEO for the Taguchi method are determined based on the values reported by Fathollahi-Fard et al. [41].

\subsection{Test instances}

Since there are not benchmark instances in the literature, different small-size and large-sized deterministic test problems are generated and depicted in Appendix C. The meta-heuristic algorithms were coded in MATLAB software on a personal computer with Core i5 processor and 8GB RAM.

\subsection{Benchmarking study}

Here, four factors are used to compare the proposed algorithms, including CPU time, quality of results, spacing metric, and diversity metric. The diversity metric factor is the maximum Euclidean distance between non-dominated solutions and the results with greater values are the better ones. Eqs. (41) and (42) are used to analyze the distribution of non-dominated answers: 
Table 2. Values of parameters.

\begin{tabular}{|c|c|c|c|}
\hline Parameter & Value & Parameter & Value \\
\hline $\operatorname{Dem}_{p}^{t}$ & $\sim U(50,100)$ & $V c p t$ & $\sim U(5,10)$ \\
\hline$D e m_{p w}^{t}$ & $\sum_{t} \sum_{p} \operatorname{Dem}_{p}^{t} / w$ & $\rho 2_{i}$ & $\sim U(0.7,0.9)$ \\
\hline$F S_{p s i}$ & $\sim U(15,20)$ & $\rho 3_{r}$ & $\sim U(0.7,0.9)$ \\
\hline In $c_{p i}$ & $\sim U(5,7)$ & Sercap $_{i}$ & $\sim U(300,600)$ \\
\hline$U S_{s i p}$ & $\sim U(10,15)$ & $\operatorname{Sern}_{i}$ & $\sim U(10,15)$ \\
\hline $\operatorname{Prc} c_{p i}$ & $\sim U(60,90)$ & $P e m i_{p i}$ & $\sim U(2,5)$ \\
\hline$R p c_{p r}$ & $\sim U(40,60)$ & $R P e m i_{p r}$ & $\sim U(2,5)$ \\
\hline$C P D C_{i}$ & $\sim U(3000,4000)$ & $R e m i_{v}$ & $\sim U(3.5,4)$ \\
\hline$C R C_{r}$ & $\sim U(2500,3500)$ & $b_{o c s} t$ & $\sim U(20,30)$ \\
\hline $\operatorname{disc}_{a b}$ & $\sim U(15,20)$ & $\mathrm{Maco}_{v}$ & $1500+0.1 \times M c a p v$ \\
\hline$d i s_{a b}$ & $\sim U(50,300)$ & $N P I_{i}$ & $\sim U(10,20)$ \\
\hline$W o c_{p}$ & $\sim U(1,3)$ & $\varphi_{1}$ & $\sim U(1,3)$ \\
\hline$\varphi_{0 p}$ & $\sim U(1.1,1.5)$ & $\varphi_{2}$ & $\sim U(1,3)$ \\
\hline$\varphi_{1 p}$ & $\sim U(0.2,0.45)$ & Icap $_{i}$ & $\sim U(100,450)$ \\
\hline$\rho 1_{i p}$ & $\sim U(0.7,0.9)$ & $M c a p_{v}$ & $\sum_{t} \sum_{p} D_{e} m_{p}^{t} / v$ \\
\hline$V U N_{p}$ & $\sim U(2,3)$ & $F p d c_{i}$ & $\sim U(200,400)$ \\
\hline$V U N_{1 p}$ & $\sim U(2,3)$ & $F r c_{r}$ & $\sim U(200,400)$ \\
\hline Spe & $\sim U(40,70)$ & ss & $\sim U(300,500)$ \\
\hline$I_{c a p}$ & $\sim U(100,450)$ & $\mu_{r t}$ & $\sim U(1,2.5)$ \\
\hline$\theta_{r}$ & $\sim U(5,10)$ & $E w e_{v}$ & $\sim U(6,10)$ \\
\hline$B N$ & 1000000 & $a c c_{v}$ & $\sim U(1,3)$ \\
\hline$\alpha s$ & $\sim U(0.8,0.95)$ & rol & $\sim U(0,1)$ \\
\hline$C \operatorname{cpu} u_{v}$ & $\sim U(4,7)$ & & \\
\hline$\varphi_{3}$ & $\sim U(1.1,1.5)$ & $B S P C_{p}$ & $\sim U(20,35)$ \\
\hline
\end{tabular}

Table 3. Optimal decisions for problem instances.

\begin{tabular}{llc}
\hline Objective function & \multicolumn{1}{c}{ Collection route } & $\begin{array}{c}\text { Optimum number of } \\
\text { objective functions }\end{array}$ \\
\hline Total costs & $s_{1} \rightarrow i_{1}$ & \\
& $s_{1} \rightarrow i_{2} \rightarrow w_{1} \rightarrow w_{2} \rightarrow w_{3} \rightarrow w_{4} \rightarrow r_{2} \rightarrow s_{1}$ & 8167389 \\
& $s_{2} \rightarrow i_{4} \rightarrow w_{5} \rightarrow w_{6} \rightarrow r_{4} \rightarrow s_{2}$ & \\
& $s_{1} \rightarrow i_{1} \rightarrow w_{1} \rightarrow w_{2} \rightarrow r_{1} \rightarrow s_{1}$ & \\
Environmental effects & $s_{1} \rightarrow i_{2} \rightarrow w_{3} \rightarrow w_{4} \rightarrow r_{2} \rightarrow s_{1}$ & \\
& $s_{2} \rightarrow i_{4} \rightarrow w_{5} \rightarrow w_{6} \rightarrow r_{4} \rightarrow s_{2}$ & \\
& & \\
Disruption risks & $s_{1} \rightarrow i_{1} \rightarrow w_{1} \rightarrow w_{2} \rightarrow w_{3} \rightarrow w_{4} \rightarrow r_{1} \rightarrow s_{1}$ & 43 \\
\hline
\end{tabular}

$$
\begin{aligned}
& \text { spacing }=\sqrt{1 / N \sum_{i=1}^{N}(d i-\bar{d})^{2}}, \\
& d i=\sum_{t=1}^{T}\left|f_{t}^{j}-f_{t}^{i}\right| \quad \forall i, j \in(1, \cdots, N) .
\end{aligned}
$$

Table 4 shows a summary of the results reached by conducting small-size test problems with metaheuristics and the BARON solver. The Average Percentage of Relative Gap (APRG) was calculated by conducting each test problem 10 times, independently. Here, Eqs. (43) and (44) are employed to calculate the gap for objective functions in order to minimize and maximize them. Table 5 demonstrates the differences between metaheuristic methods in dealing with largesize test problems. Of note, due to the complexity of the test problems, exact method was unable to solve them.

$G a p \%=\left(O F V_{\text {meta }}-O F V_{\text {Exact }}\right) / O F V_{\text {Exact }} 100$ 
Table 4. APRG for small-size test problems with HPSO-SEO and NSGA-II.

\begin{tabular}{|c|c|c|c|c|c|c|}
\hline \multirow{3}{*}{$\begin{array}{c}\text { Problem } \\
\text { number }\end{array}$} & \multicolumn{3}{|c|}{ HPSO-SEO } & \multicolumn{3}{|c|}{ NSGA-II } \\
\hline & \multicolumn{3}{|c|}{ GAP\% } & \multicolumn{3}{|c|}{ GAP $\%$} \\
\hline & Obj 1 & Obj 2 & Obj 3 & Obj 1 & Obj 2 & Obj3 \\
\hline $\mathrm{S} 1$ & 0.01 & 0.02 & 0.01 & 0.03 & 0.07 & 0.07 \\
\hline $\mathrm{S} 2$ & 0.094 & 0.076 & 0.091 & 0.17 & 0.198 & 0.151 \\
\hline $\mathrm{S} 3$ & 0.25 & 0.33 & 0.22 & 0.42 & 0.53 & 0.67 \\
\hline $\mathrm{S} 4$ & 0.43 & 0.66 & 0.56 & 0.84 & 1.18 & 1.06 \\
\hline S5 & 1.05 & 1.16 & 0.81 & 1.66 & 1.73 & 1.53 \\
\hline $\mathrm{S} 6$ & 1.48 & 1.23 & 1.55 & 2.17 & 2.29 & 1.82 \\
\hline $\mathrm{S} 7$ & 1.73 & 1.66 & 1.76 & 2.52 & 2.72 & 2.28 \\
\hline $\mathrm{S} 8$ & 2.05 & 2.11 & 2.27 & 2.94 & 3.13 & 2.73 \\
\hline $\mathrm{S} 9$ & 2.56 & 2.21 & 2.39 & 3.34 & 3.32 & 3.17 \\
\hline $\mathrm{S} 10$ & 2.74 & 2.46 & 2.51 & 3.51 & 3.64 & 3.33 \\
\hline
\end{tabular}

Table 5. APRG for large-size test problems with HPSO-SEO and NSGA-II.

\begin{tabular}{cccc}
\hline \multirow{2}{*}{$\begin{array}{c}\text { Problem } \\
\text { number }\end{array}$} & \multicolumn{3}{c}{ HPSO-SEO VS. NSGA-II } \\
\cline { 2 - 4 } & Gbj 1 & Obj 2 & Obj 3 \\
\hline L1 & 4.17 & 4.21 & 4.31 \\
L2 & 5.24 & 5.54 & 5.17 \\
L3 & 6.59 & 6.65 & 5.91 \\
L4 & 7.95 & 7.57 & 6.89 \\
L5 & 8.11 & 8.54 & 7.35 \\
L6 & 9.43 & 9.37 & 8.36 \\
L7 & 10.75 & 10.05 & 9.47 \\
L8 & 11.64 & 11.64 & 10.74 \\
L9 & 12.76 & 12.34 & 11.94 \\
L10 & 13.47 & 13.23 & 12.38 \\
\hline
\end{tabular}

$G a p \%=\left(O F V_{m e t a}-O F V_{p M O P S O}\right) / O F V_{p M O P S O} 100$.

The results prove the efficiency of the HPSO-SEO algorithm compared to NSGA-II in reaching nearoptimum solutions to large-size instances. To recount in more detail, the means of gaps achieved by the HPSO-SEO for the objective functions of small-size instances are 1.2, 1.19, and 1.21 and the same values with the NSGA-II method are 1.7, 1.8, and 1.6. In addition, the means of gaps with the HPSO-SEO for the objective functions of large-size instances are $1.7,1.9$, and 1.8, which approve the superiority of the HPSO-SEO. Based on Figures 4 to 7, HPSO$\mathrm{SEO}$ is able to reach better solutions with higher

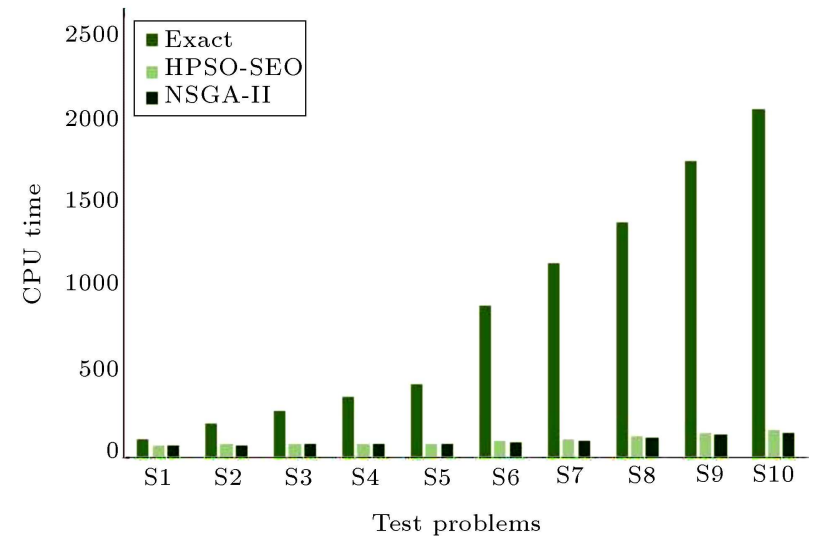

Figure 4. CPUC times of the HPSO-SEO, NSGA-II, and exact method.

uniformity in the solution space. However, this algorithm needs more time to search the solution area and find near-optimum solutions to large-size problems than does the NSGA-II algorithm. On the other hand, the diversity of the NSGA-II results is higher.

\subsection{Case study}

Here, the logistics of a major manufacturer of analog and digital equipment and radio transmitters in Iran are assessed as the case of our study. The active assembly section of the company receives some parts from other suppliers and use them in the final assembly of more efficient products. The items produced at this unit include high-power 100 and 200 watt transmitters, Remux DVBT2/DVBS2 receivers, and PVRs (Personal Video Recorders). Logical decisions for the problem are determined to reduce the total costs besides the environmental and social issues related with the system. 


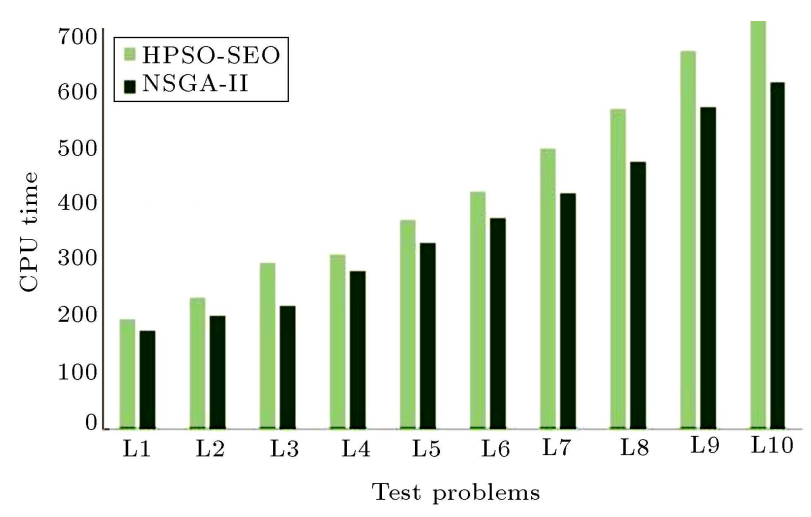

Figure 5. CPU times of HPSO-SEO and NSGA-II.

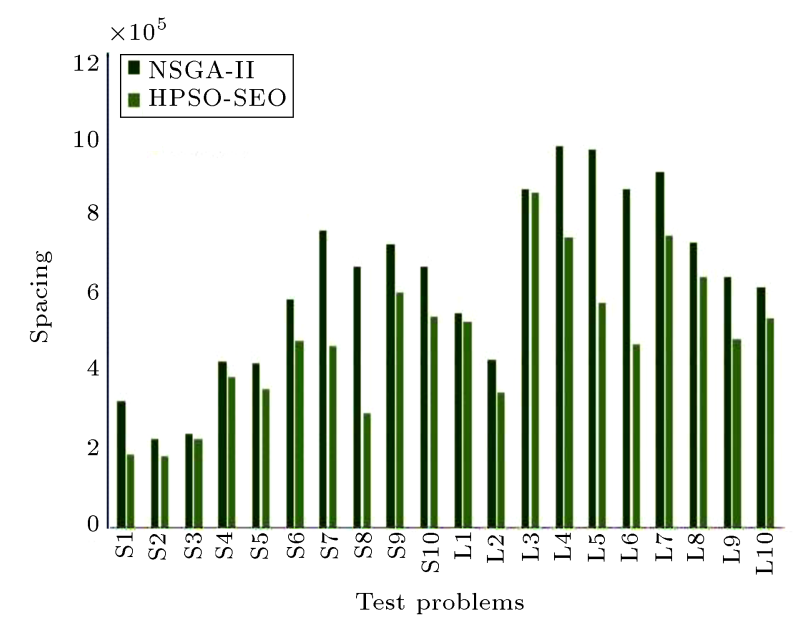

Figure 6. Results of spacing with HPSO-SEO and NSGA-II.

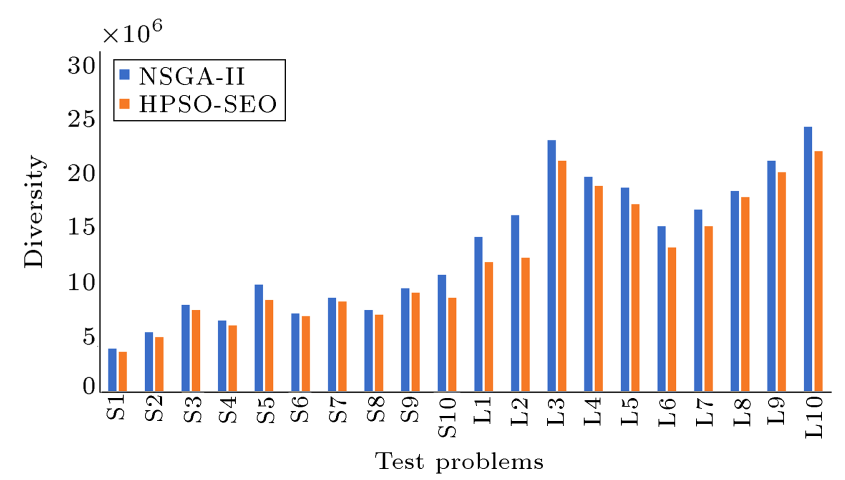

Figure 7. Results of diversity with HPSO-SEO and NSGA-II.

The mentioned company is faced with the challenge of reducing the related costs of shipment, production, and storage. Considering the public concerns about the environmental and social issues besides legislation around green production, the mentioned company has some similarities to the proposed model in the current study. To select the nominated PDC and RC centers, a fuzzy clustering method is applied.

Here, shipment times and distances of nodes are determined by means of Google maps. The demand of commodities and establishment cost of centers are reached using the information registered in the company. The damage rate caused by disruption in each city is obtained from the existing statistical data. Environmental parameters are determined by considering the mentioned vehicles and fuzzy parameters are set based on previous experience. Applying uniform distribution, other random numbers are calculated to set the optimistic and pessimistic numbers for uncertain parameters. The proposed HPSO-SEO algorithm is used to solve the problem. It should be noted that circular symbols are related to the position of local retailers and the square symbols denote the cluster centers.

\subsubsection{Sensitivity analysis}

Here, the robustness of the outcome reached by the proposed method are analyzed for 7 small-size test problems. The values for the parameters are determined using Table 2 based on the ranges for trapezoidal fuzzy numbers. The results in Table 6 show that the RPP approach reaches better results for various amounts of uncertainty in different ranges of test problems. It is necessary to mention that, for further analysis, the RPP method is used to deal with uncertainties $(\eta 1=\eta 2=4000000$ and $\xi=0.8$ ).

Next, the proposed model is applied to the case study and different analyses are conducted as follows. Figure 8 shows increasing the transportation cost variations, denoted by $\psi_{1}$, results in establishing more PDCs and RCs to decrease the transportation costs and enhance the $O F V_{3}$. Based on Figure 9, increasing inventory cost variations, denoted by $\psi_{2}$, leads to establishing fewer PDCs and RCs to reduce the related production-inventory costs and decrease $\mathrm{OFV}_{3}$. Figures 10 and 11 demonstrate the changes in $O F V_{1}$ and $O F V_{2}$ with changes in $\psi_{1}$ and $\psi_{2}$. The related results reveal that increasing $\psi_{1}$ will enhance $O F V_{1}$ and reduce $O F V_{2}$, simultaneously. Also, increasing $\psi_{2}$ will lead to the reduction of $O F V_{1}$ and increase in $O F V_{2}$.

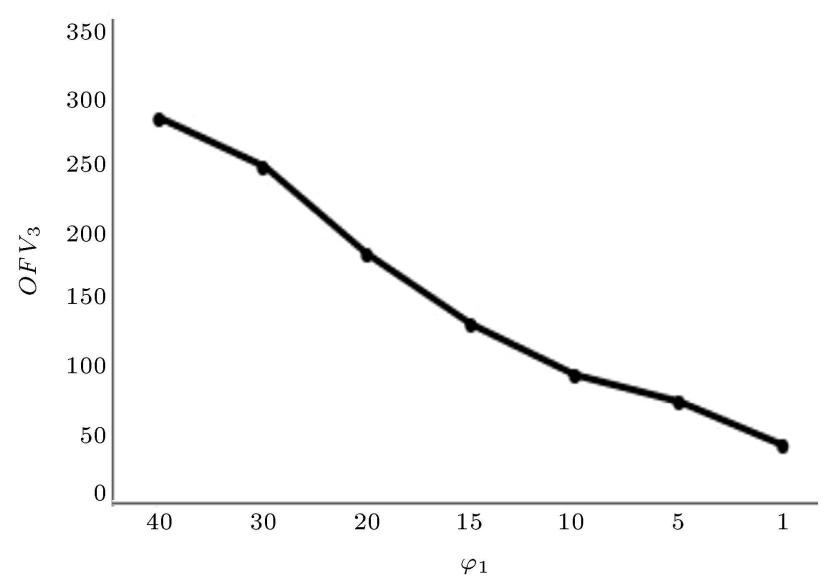

Figure 8. Variations of $O F V_{3}$ vs. transportation cost. 
Table 6. Results of the provided solutions.

\begin{tabular}{|c|c|c|c|c|c|c|c|c|c|c|c|c|}
\hline \multirow{2}{*}{$\begin{array}{c}\text { Test } \\
\text { problem }\end{array}$} & \multicolumn{3}{|c|}{ PCCP 0.7} & \multicolumn{3}{|c|}{ РCCP 0.8} & \multicolumn{3}{|c|}{ PCCP 0.9} & \multicolumn{3}{|c|}{ RPP } \\
\hline & $O F V_{1}$ & $\mathrm{OFV} \mathrm{V}_{2}$ & $\mathrm{OFV}$ & $O F V_{1}$ & $\mathrm{OFV}$ & $\boldsymbol{O F} V_{3}$ & $O F V_{1}$ & $\boldsymbol{O F} \boldsymbol{V}_{2}$ & $\boldsymbol{O F V _ { 3 }}$ & $O F V_{1}$ & $\mathrm{OFV} \mathrm{V}_{2}$ & $\boldsymbol{O F} V_{3}$ \\
\hline S1 & 8554379 & 50442 & 27 & 8353675 & 50456 & 25 & 8253567 & 50326 & 22 & 8106345 & 49857 & 19 \\
\hline $\mathrm{S} 2$ & 8577623 & 53799 & 30 & 8397653 & 53793 & 30 & 8263456 & 53762 & 28 & 8123450 & 52462 & 23 \\
\hline S3 & 8689750 & 57769 & 54 & 8489654 & 57662 & 53 & 8389657 & 57654 & 50 & 8296792 & 56432 & 47 \\
\hline S4 & 15162432 & 63591 & 59 & 14163124 & 63587 & 58 & 13145678 & 63556 & 56 & 12234598 & 62341 & 53 \\
\hline $\mathrm{S} 5$ & 17341322 & 75643 & 73 & 16345675 & 75632 & 73 & 15324562 & 75543 & 71 & 14432567 & 74321 & 68 \\
\hline S6 & 19213865 & 86753 & 86 & 18213564 & 86674 & 85 & 17221356 & 86543 & 82 & 16754327 & 85392 & 77 \\
\hline S7 & 20963755 & 93467 & 91 & 19963453 & 93435 & 91 & 18954432 & 93221 & 86 & 17543667 & 92344 & 81 \\
\hline
\end{tabular}

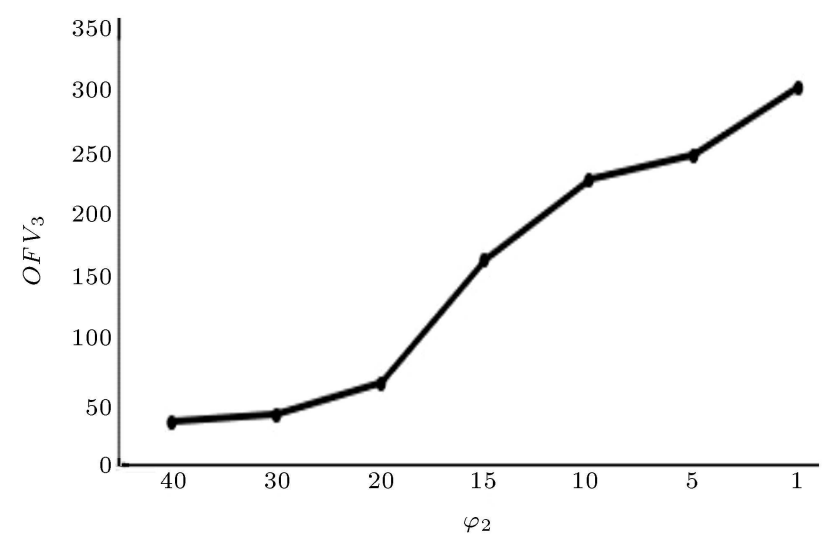

Figure 9. Variations of $O F V_{3}$ vs. inventory cost.

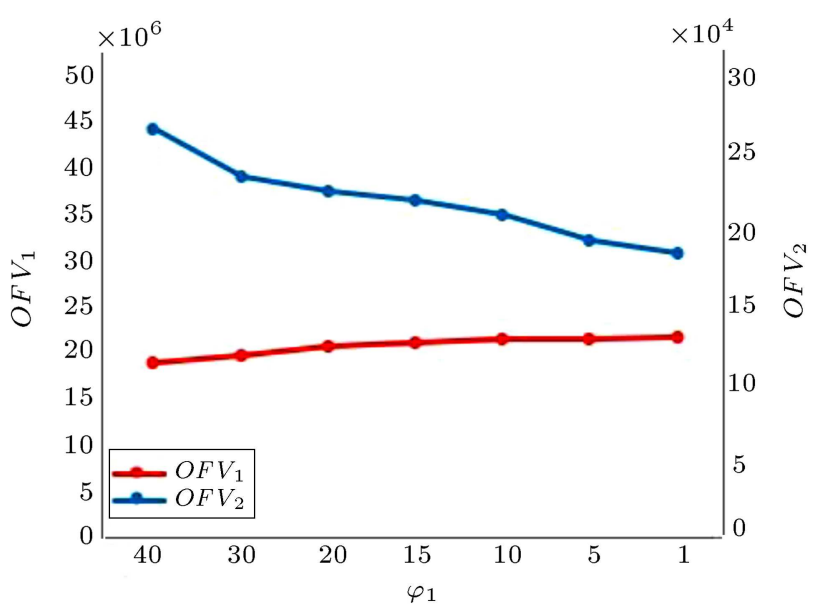

Figure 10. Variations of $O F V_{1}$ and $O F V_{2}$ vs. transportation cost.

Figure 12 demonstrates the performance of the queue approach in calculating TWC for different values of $\varphi_{1 p}$. To assess the results, two scenarios are designed. In the first scenario, a queue structure is considered to calculate TWC. In second scenario, TWC is calculated by disregarding the queue structure. The results prove the efficiency of the queueing system in describing the TWC. In addition, Figures 13 to 15 show the effect of changing the related emission of greenhouse gases

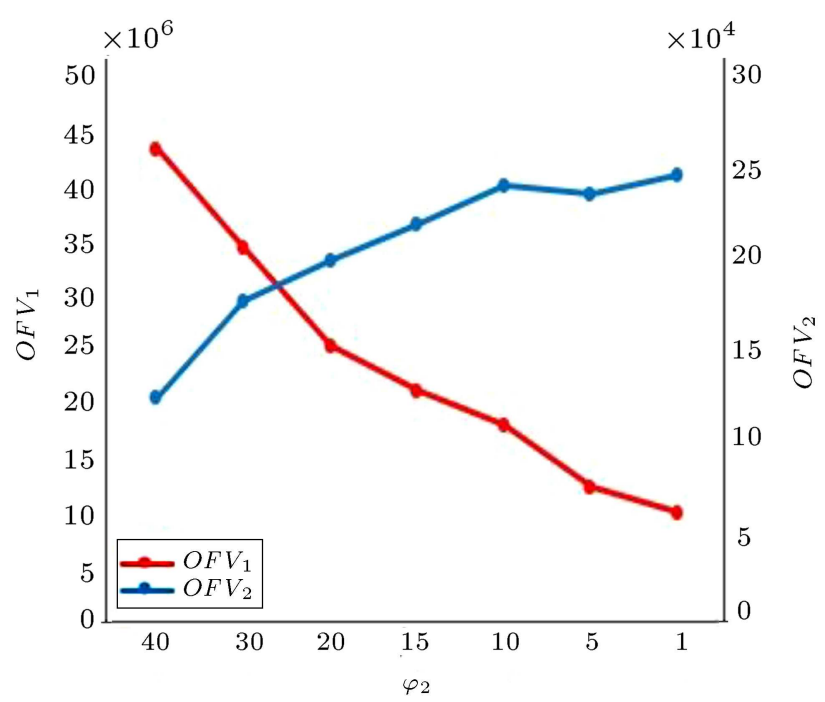

Figure 11. Variations of $O F V_{1}$ and $O F V_{2}$ vs. inventory cost.

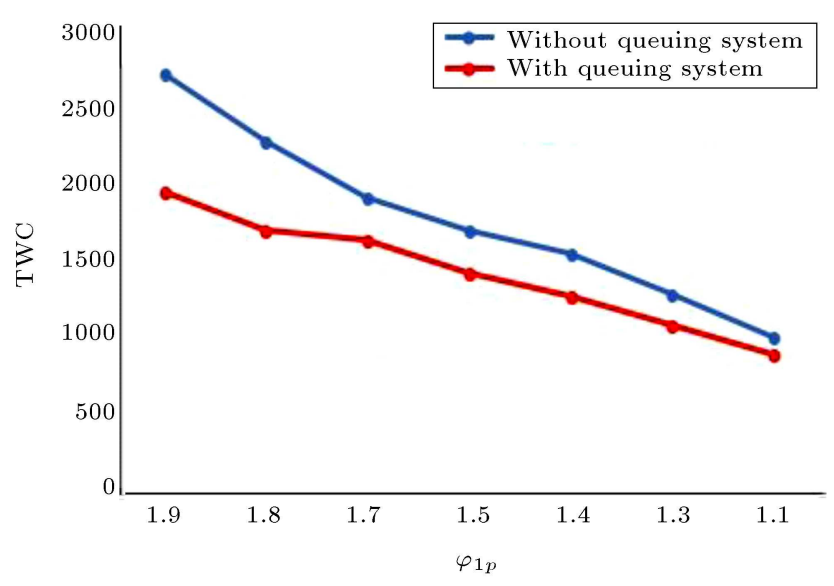

Figure 12. TWC vs. the coefficient of reproduced items.

on the results of each objective function, separately, indicating a reverse correlation between the first and second objective functions of the model.

Table 7 shows the results of the model by changing the parameters related with disruption. According to the results, reducing the mentioned parameters 
Table 7. Results of the model for different values of disruption with $\eta 1=\eta 2=4000000$ and $\xi=0.8$.

\begin{tabular}{cllll}
\hline Test problem=S10 & \multicolumn{5}{c}{ The most likely value } \\
\hline$\varphi_{1}=\varphi_{2}=\varphi_{3}$ & 1.4 & 1.3 & 1.2 & 1.1 \\
\hline$\rho 2_{i}=\rho 3_{r}$ & 0.2 & 0.4 & 0.6 & 0.8 \\
\hline OF $V_{1}$ & 31325987 & 28674389 & 24872234 & 22875340 \\
OF $V_{2}$ & 184563 & 187829 & 199482 & 204218 \\
OF $V_{3}$ & 198 & 180 & 171 & 152 \\
Backup PDC centers & 8 & 7 & 4 & 2 \\
Backup RC centers & 4 & 3 & 2 & 1 \\
\hline
\end{tabular}

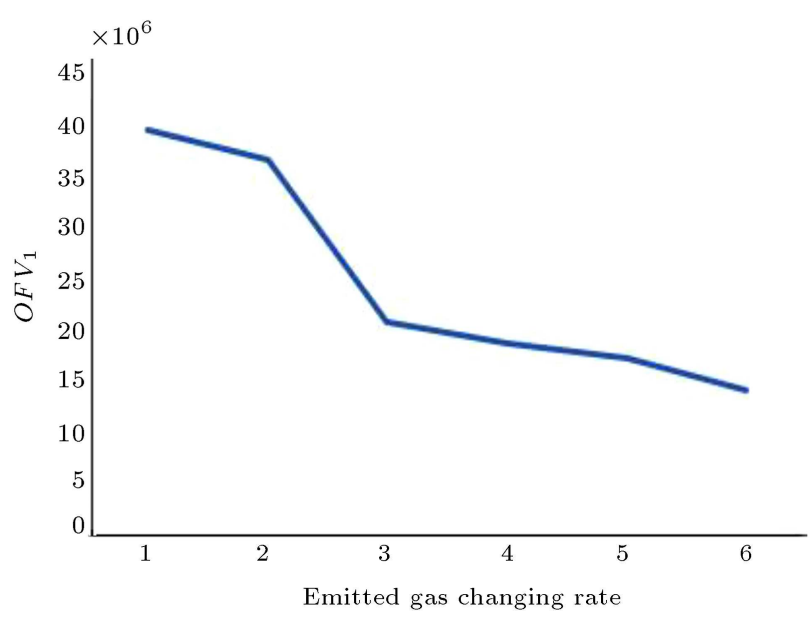

Figure 13. $O F V_{1}$ vs. changing rate of the emitted gas.

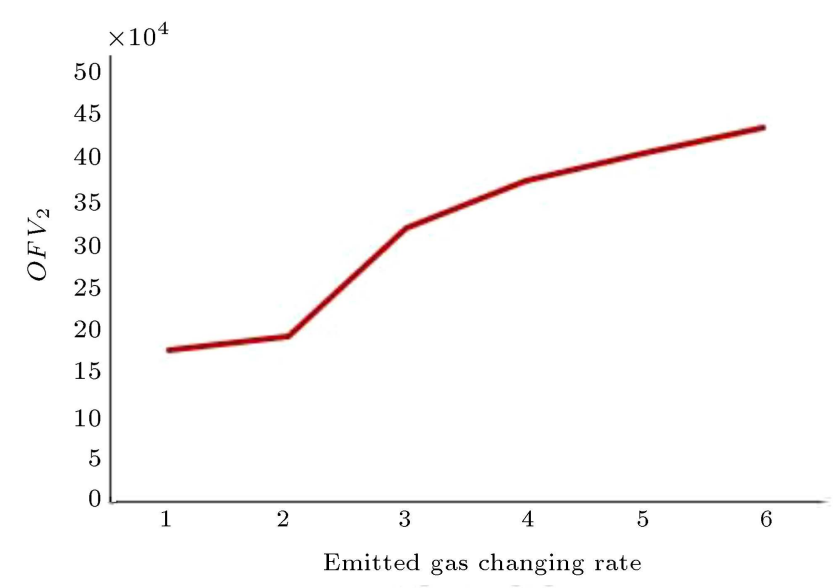

Figure 14. $O F V_{2}$ vs. changing rate of the emitted gas.

increases the $O F V_{1}, O F V_{3}$, and the number of backup centers. However, $O F V_{2}$ decreases as the values of disruption parameters is reduced.

\section{Conclusion}

This paper proposes a novel data-driven agile sustainable Closed-Loop Supply Chain (CLSC) model to

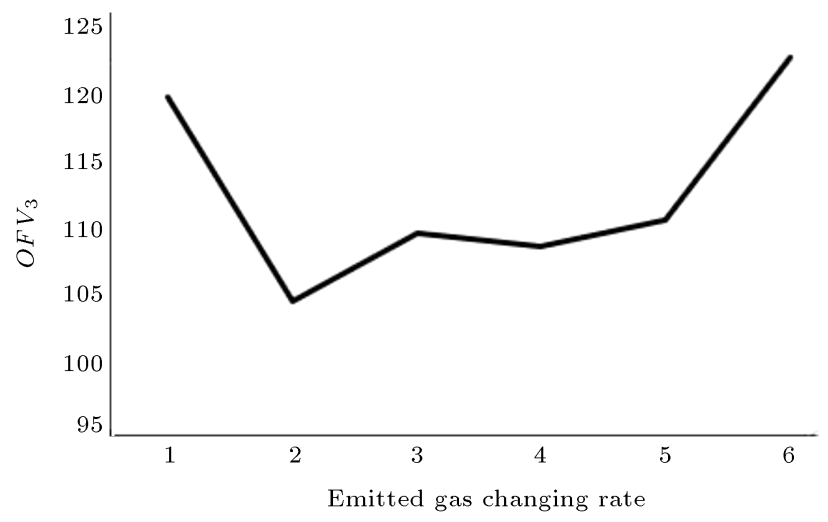

Figure 15. $O F V_{3}$ vs. changing rate of the emitted gas.

find a compromise solution among the economic, environmental, and social objective functions. The main contributions of this study include: simultaneously addressing routing, inventory, lot sizing, reproduction, and location-allocation decisions besides the capacity constraints; considering economic, green, leanness, agility, and social factors, concurrently; regarding the strategic and operational decisions in order to decrease the impact of disruptions; proposing a robust possibilistic programming approach to dealing with uncertainty; using the FCCM to select the potential locations for establishing production, distribution, and reproduction centers based on proximity to the local retailers; and applying the HPSO-SEO algorithm to solve large-size instances with high performance. Noteworthy, developing a model based on lean manufacturing supports the environmental aspects of production. In addition, including agile manufacturing strategies is aligned with the aim of increasing the resiliency of systems against the risk of disruptions.

The performance of the proposed metaheuristic algorithms was compared with an exact solver in case of quality and processing time. The results proved the superiority of the HPSO-SEO algorithm in case of quality and spacing metrics, while the CPU time with NSGA-II was shorter. The introduced case 
study showed the applicability of the model to real situations. Furthermore, some sensitivity analyses were implemented to analyze the behaviour of the model under different situations. The results revealed that social risks had direct relationship with transportation cost and inverse relationship with inventory cost. Also, shipment cost led to increase in the total cost and decrease in the environmental effects. The results of increasing inventory cost were inverse. In addition, we utilized a queueing system to decrease the elapsed time of trucks in loading/unloading the cargo at the centers and lapsed time due to road blocking. Disruption also had a significant effect on the economic aspect of the problem and damages caused by disruption increased the total costs of the system. It should be added that variation of emitted gases could lead to a reverse correlation between the first and second objective functions. However, the slope of changes and variations was sharper for the first objective function, meaning that changing the amount of emitted greenhouse gases could have greater impact on the financial aspects of the system.

For the future studies, considering other aspects of lean/agile production, designing a resilient supply chain, considering the perishability of products, and developing other heuristic and exact solution approaches to the CLCS problem can be interesting topics of research.

\section{References}

1. Dehghanian, F. and Mansour, S. "Designing sustainable recovery network of end-of-life products using genetic algorithm", Res., Conse. Recy., 53(10), pp. 559-570 (2009).

2. Sahebjamnia, N., Fathollahi-Fard, A.M., and Hajiaghaei-Keshteli, M. "Sustainable tire closed-loop supply chain network design: Hybrid metaheuristic algorithms for large-scale networks", Jour. Clea. Prod., 196, pp 273-296 (2018).

3. Widyadana, G.A. and Irohara, T. "Modelling multitour inventory routing problem for deteriorating items with time windows", Scientia Iranica, 26(2), pp. 932941 (2019).

4. Esfandiyari, Z., Bashiri, M., and TavakkoliMoghaddam, R. "Resilient network design in a location-allocation problem with multi-level facility hardening", Scientia Iranica, 26(2), pp. 996-1008 (2019).

5. Veysmoradi, D., Vahdani, B., Sartangi, M.F., et al. "Multi-objective open location-routing model for relief distribution networks with split delivery and multi-mode transportation under uncertainty", Scientia Iranica, Transactions E, Industrial Engineering, 25(6), pp. 3635-3653 (2018).

6. Pan, Z., Tang, J., and Liu, O. "Capacitated dynamic lot sizing problems in closed-loop supply chain", Eur. J. Ope. Res., 198(3), pp. 810-821 (2009).

7. Soleimani, H. and Kannan, G. "A hybrid particle swarm optimization and genetic algorithm for closedloop supply chain network design in large-scale networks", Appl Math Model, 39(14), pp. 3990-4012 (2015).

8. Kannan, G., Sasikumar, P., and Devika, K. "A genetic algorithm approach for solving a closed loop supply chain model: A case of battery recycling", Appl Math Model, 34(3), pp. 655-670 (2010).

9. Torkaman, S., Ghomi, S.F., and Karimi, B. "Multistage multi-product multi-period production planning with sequence-dependent setups in closed-loop supply chain", Computers \& Industrial Engineering, 113, pp. 602-613 (2017).

10. As'ad, R., Hariga, M., and Alkhatib, O. "Two stage closed loop supply chain models under consignment stock agreement and different procurement strategies", Appl. Math. Model, 65, pp. 164-186 (2019).

11. Hasanov, P., Jaber, M.Y., and Tahirov, N. "Four-level closed loop supply chain with remanufacturing", Appl Math Model, 66, pp. 141-155 (2019).

12. Hajiaghaei-Keshteli, M. and Fathollahi-Fard, A.M. "Sustainable closed-loop supply chain network design with discount supposition", Neur. Comp. Appli., 31(9), pp. 5343-5377 (2019).

13. Taleizadeh, A.A., Haghighi, F., and Niaki, S.T.A. "Modeling and solving a sustainable closed loop supply chain problem with pricing decisions and discounts on returned products", Jour. Clea. Prod., 207, pp. 163181 (2019).

14. Safaeian, M., Fathollahi-Fard, A.M., Tian, G., et al. "A multi-objective supplier selection and order allocation through incremental discount in a fuzzy environment", Journal of Intelligent \& Fuzzy Systems, 37(1), pp. 1435-1455 (2019).

15. Fathollahi-Fard, A.M., Govindan, K., HajiaghaeiKeshteli, M., et al. "A green home health care supply chain: New modified simulated annealing algorithms", Jour. Clea. Prod., 240, P. 118200 (2019).

16. Feng Zhang, Y., Tian, G., Fathollahi-Fard, A.M., et al. "A novel hybrid fuzzy grey TOPSIS method: Supplier evaluation of a collaborative manufacturing enterprise", App. Sci., 9(18), p. 3770 (2019).

17. Liu, X., Tian, G., Fathollahi-Fard, A.M., et al. "Evaluation of ship's green degree using a novel hybrid approach combining group fuzzy entropy and cloud technique for the order of preference by similarity to the ideal solution theory", Clea. Tech. Envi. Pol., 22(2), pp. 493-512 (2020). 
18. Fathollahi-Fard, A.M., Hajiaghaei-Keshteli, M., and Mirjalili, S. "Multi-objective stochastic closed-loop supply chain network design with social considerations", Аpp. So. Compu., 71, pp. 505-525 (2018).

19. Araee, E., Manavizadeh, N., and Aghamohammadi Bosjin, S. "Designing a multi-objective model for a hazardous waste routing problem considering flexibility of routes and social effects", Jour. Ind. Prod. Eng., 37(1), pp. 33-45 (2020).

20. Aghamohammadi-Bosjin, S., Rabbani, M., TavakkoliMoghaddam, R. "Agile two-stage lot-sizing and scheduling problem with reliability, customer satisfaction and behaviour under uncertainty: a hybrid metaheuristic algorithm", Engineering Optimization, 52(8), pp. 1323-1343 (2020).

21. Fathollahi-Fard, A.M., Hajiaghaei-Keshteli, M., Tian, G., et al. "An adaptive Lagrangian relaxation-based algorithm for a coordinated water supply and wastewater collection network design problem", Info. Scien., 512, pp. 1335-1359 (2020).

22. Fahimnia, B., Sarkis, J., Dehghanian, F., et al. "The impact of carbon pricing on a closed-loop supply chain: an Australian case study", J. Clean. Prod., 59, pp. 210-225 (2013).

23. Govindan, K., Jafarian, A., and Nourbakhsh, V. "Biobjective integrating sustainable order allocation and sustainable supply chain network strategic design with stochastic demand using a novel robust hybrid multiobjective metaheuristic", Comput. Oper. Res., 62, pp. 112-130 (2015).

24. Mokhtari, H. and Hasani, A. "A multi-objective model for cleaner production-transportation planning in manufacturing plants via fuzzy goal programming", J. Manuf. Syst., 44, pp. 230-242 (2017).

25. Chalmardi, M.K. and Camacho-Vallejo, J.F. "A bilevel programming model for sustainable supply chain network design that considers incentives for using cleaner technologies", J. Clean. Prod., 213, pp. 10351050 (2019).

26. Ciccullo, F., Pero, M., and Caridi, M. "Exploring the hidden potential of product design to mitigate supply chain risk", Int. J. Elect. Custo Rela Manag., 11(1), pp. 66-93 (2017).

27. Cardoso, S.R., Barbosa-Póvoa, A.P., Relvas, S., et al. "Resilience metrics in the assessment of complex supply-chains performance operating under demand uncertainty", Omega, 56, pp. 53-73 (2015).

28. Mohammaddust, F., Rezapour, S., Farahani, R.Z., Mofidfar, M., et al. "Developing lean and responsive supply chains: A robust model for alternative risk mitigation strategies in supply chain designs", Int. J. Prod. Econ., 183, pp. 632-653 (2017).
29. Rohaninejad, M., Sahraeian, R., and TavakkoliMoghaddam, R. "Multi-echelon supply chain design considering unreliable facilities with facility hardening possibility", Appl. Math. Model, 62, pp. 321-337 (2018).

30. Ghobadi, M., Arkat, J., and Tavakkoli-Moghaddam, R. "Hypercube queuing models in emergency service systems: A state-of-the-art review", Scientia Iranica. Transactions E, Industrial Engineering, 26(2), pp. 909-931 (2019).

31. Vahdani, B., Tavakkoli-Moghaddam, R., Modarres, M., et al. "Reliable design of a forward/reverse logistics network under uncertainty: a robust-M/M/c queuing model", Transport Res. E-Log, 48(6), pp. 1152-1168 (2012).

32. Saeedi, S., Mohammadi, M., and Torabi, S. "A De Novo programming approach for a robust closed-loop supply chain network design under uncertainty: An M/M/1 queueing model", Int. J. Ind. Eng. Comput., 6(2), pp. 211-228 (2015).

33. Vidani, B. and Mohammadi, M. "A bi-objective interval-stochastic robust optimization model for designing closed loop supply chain network with multipriority queuing system", Int. J. Prod. Econ., 170, pp. 67-87 (2015).

34. Mousazadeh, M., Torabi, S., and Zahiri, B. "A robust possibilistic programming approach for pharmaceutical supply chain network design", Comput. Chem. Eng., 82, pp. 115-128 (2015).

35. Sadghiani, N.S., Torabi, S., and Sahebjamnia, N. "Retail supply chain network design under operational and disruption risks", Transport Res E-Log, 75, pp. 95-114 (2015).

36. Kim, J., Do Chung, B., Kang, Y., and Jeong, B. "Robust optimization model for closed-loop supply chain planning under reverse logistics flow and demand uncertainty", J. Clean. Prod., 196, pp. 1314-1328 (2018).

37. Hajipour, V., Tavana, M., Di Caprio, D., et al. "An optimization model for traceable closed-loop supply chain networks", Appl. Math. Model, 71, pp. 673-699 (2019).

38. Ramezani, M., Bashiri, M., and TavakkoliMoghaddam, R. "A new multi-objective stochastic model for a forward/reverse logistic network design with responsiveness and quality level", Appl. Math. Mod., 37(1-2), pp. 328-344 (2013).

39. Escobar, J.W., Linfati, R., and Toth, P. "A two-phase hybrid heuristic algorithm for the capacitated locationrouting problem", Comput. Oper. Res., 40(1), pp. 7079 (2013). 
40. Karimi, B., Ghomi, S.F., and Wilson, J.M. "The capacitated lot sizing problem: a review of models and algorithms", Omega, 31(5), pp. 365-378 (2003).

41. Fathollahi-Fard, A.M., Hajiaghaei-Keshteli, M., and Tavakkoli-Moghaddam, R. "The social engineering optimizer (SEO)", Eng. Appl. Artif. Intel., 72, pp. 267-293 (2018).

42. Zhang, X., Du, K.J., Zhan, Z.H., et al. "Cooperative coevolutionary bare-bones particle swarm optimization with function independent decomposition for largescale supply chain network design with uncertainties", IEEE Transactions on Cybernetics, 50(10), pp. 44544468 (2019).

43. Baliarsingh, S.K., Ding, W., Vipsita, S., et al. "A memetic algorithm using emperor penguin and social engineering optimization for medical data classification", Appl. Sof. Comp., 85, p. 105773 (2019).

44. Fathollahi-Fard, A.M., Ranjbar-Bourani, M., Cheikhrouhou, N., and Hajiaghaei-Keshteli, M. "Novel modifications of social engineering optimizer to solve a truck scheduling problem in a cross-docking system", Comp. Indus. Eng., 137, p. 106103 (2019).

\section{Appendix A}

\section{Indices}

$p, p^{\prime} \quad$ Products $p=\{1.2 . \cdots . P\}$

$i, j \quad$ PDCs $i=\{1.2 . \cdots . I\}, j=\{1.2 . \cdots . J\}$

$r, q \quad \operatorname{RCs} r=\{1.2 . \cdots . R\}, q=\{1.2 . \cdots . Q\}$

$t \quad$ Time periods $t=\{1.2 . \cdots . T\}$

$h \quad$ Potential locations $h=\{1.2 . \cdots . H\}$

$w, u \quad$ Retailers $w=\{1.2 . \cdots . W\}$, $u=\{1.2 . \cdots . U\}$

$s \quad$ Suppliers $s=\{1.2 . \cdots . S\}$

$a, b \quad$ Nodes

$v \quad$ Vehicles $v=\{1.2 . \cdots . V\}$

$Z \quad$ Total retailers and potential centers

\section{Parameters}

$\operatorname{Dem}_{p}^{t} \quad$ Demand for product $(p)$ in period $(t)$

$D_{e m}^{t} \quad$ Retailors' demand for product $(p)$

$F S_{p s i} \quad$ Constant order cost for raw material

$(p)$ requested by $\mathrm{PDC}(i)$ to supplier

$(s)$

In $c_{p i} \quad$ Holding cost of product $(p)$ in PDC $(i)$

$U S_{\text {sip }} \quad$ Transportation cost for raw material

$(p)$ requested by $\mathrm{PDC}(i)$ from supplier $(s)$

$\operatorname{Prc}_{p i} \quad$ Production cost of product $(p)$ in PDC (i)

$R p c_{p r} \quad$ Reproduction cost of product $(p)$ in $\mathrm{RC}(r)$
$C P D C_{i} \quad$ Opening cost of $\operatorname{PDC}(i)$

$C R C_{r} \quad$ Opening cost of RC $(r)$

$\operatorname{disc}_{a b} \quad$ Shipment cost between the node $(a)$ and the node $(b)$

$d i s_{a b} \quad$ Distance of node $(a)$ and node $(b)$

$W o c_{p} \quad$ Relative importance of product $(p)$

$\varphi_{1 p} \quad$ Amount of product $(p)$ to be reproduced

$\varphi_{0 p} \quad$ Amount of raw material for product $(p)$

$\rho 1_{i p} \quad$ Production capacity for product $(p)$ in PDC $(i)$ due to disruption

$\rho 2_{i} \quad$ The coefficient determining the PDC (i) capacity due to disruption

$\rho 3_{r} \quad$ The coefficient determining the RC $(r)$ capacity due to disruption

Sercap $_{i} \quad$ Production capacity of PDC $(i)$

Pemi $i_{\text {pi }} \quad$ Amount of emitted $\mathrm{CO}_{2}$ for production of a single product $(p)$ in $\mathrm{PDC}(i)$

RPemi $i_{p r}$ Amount of emitted $\mathrm{CO}_{2}$ for reproduction of a single product $(p)$ in $\mathrm{RC}(r)$

Remi $\quad$ Amount of emitted $\mathrm{CO}_{2}$ by vehicle $(v)$ per unit of distance traveled

bocs $s_{p t} \quad$ Shortage cost of product $(p)$ in period $(t)$

$M \quad$ Fixed cost of vehicle $(v)$ usage

$N P I_{i} \quad$ Number of injured people due to disruption in $\mathrm{PDC}(i)$

$\varphi_{1} \quad$ Number of injured people in PDC $(i)$ due to disruption

$\varphi_{2} \quad$ Number of injured people in RC $(r)$ due to disruption

Icap $_{i} \quad$ Maximum capacity for the storage of PDC $(i)$ to hold inventories

Mcap $_{v} \quad$ Maximum capacity for vehicle $(v)$ to ship products

$V U N_{p} \quad$ The amount of space required per unit of product $(p)$

$V U N_{1 p} \quad$ The amount of space required per unit of reproduction $(p)$

Icap $_{i} \quad$ Total capacity of PDC $(i)$ to keep products

Icap $\quad$ Total capacity of $\mathrm{RC}(r)$ to keep products

$B N \quad$ Big number

$\alpha s \quad$ Service level

$F p d c_{i} \quad$ Backup facility cost to fortify and expand the storage capacity of PDC (i) 
$\begin{array}{ll}F r c_{r} & \begin{array}{l}\text { Backup facility cost to fortify and } \\ \text { expand the storage capacity of RC }(r)\end{array} \\ s s & \text { Amount of space added to the } \\ & \text { warehouse of PDCs and RCs as a } \\ & \text { resilient strategy } \\ a c c_{v} & \text { Acceleration of vehicle } v \\ r o l & \text { Factor determining rolling resistance } \\ E w e_{v} & \text { Weight of unused parts for vehicle } v \\ B S P C_{p} & \begin{array}{l}\text { Backup supplier assignment cost for } \\ \text { product }(P)\end{array} \\ C c p u_{v} & \text { Cost of shipping each item by vehicle } v\end{array}$

\section{Decision variables}

$X_{\text {pit }} \quad$ Number of products $(p)$ produced at $\operatorname{PDC}(i)$ in period $(t)$

Invit Number of products $(p)$ held at PDC (i) in period $(t)$

$b_{\text {pit }} \quad$ Shortage of product $(p)$ at PDC $(i)$ in period $(t)$

$E X S_{p t} \quad 1$ if a backup supplier is assigned to product $(p)$ in period $(t)$; 0 otherwise

Rout $_{a b v}^{t} \quad 1$ if nodes $(a)$ and $(b)$ are connected by vehicle $(v)$ in period $(t) ; 0$ otherwise

$P O_{h i} \quad 1$ if PDC $(i)$ is founded in location (h); 0 otherwise

$R O_{h r} \quad 1$ if $\mathrm{RC}(r)$ is founded in location (h); 0 otherwise

$R X_{s i} \quad 1$ if $\operatorname{PDC}(i)$ is related to supplier $(i)$; 0 otherwise

$R Z_{s r} \quad 1$ if $\mathrm{RC}(r)$ is related to supplier $(i) ; 0$ otherwise

$A X_{i w} \quad 1$ if retailor $(w)$ is related to $\operatorname{PDC}(i)$; 0 otherwise

$B X_{w r} \quad 1$ if returned items of retailor $(w)$ are shipped to $\mathrm{RC}(r)$; 0 otherwise

$X_{\text {psit }}^{0} \quad$ Number of the needed raw materials received from supplier $(s)$ for product $(p)$ at $\mathrm{PDC}(i)$ in period $(t)$ $\hat{x}_{p s^{\prime} i t}^{0} \quad$ Number of raw materials received from backup supplier $\left(s^{\prime}\right)$ for product $(p)$ at $\operatorname{PDC}(i)$ in period $(t)$

$X_{p} i r t^{1} \quad$ Total number of returns for product $(p)$ produced at PDC $(i)$ connected with $\mathrm{RC}(r)$ in period $(t)$

$X p d c_{i} \quad 1$ if a backup storage is assigned to PDC (i); 0 otherwise

$X r c_{r} \quad 1$ if a backup storage is assigned to RC $(r) ; 0$ otherwise

$L A O_{i w v}^{t} \quad$ Amount of cargo shipped from PDC $(i)$ to retailor $(w)$ by vehicle $(v)$

\section{Appendix B}

\section{Parameters}

$\theta_{r / i} \quad$ Number of operators at RC $(r) / \mathrm{PDC}$ (i)

$\mu_{r / i t} \quad$ Operation rate of $\mathrm{RC}(r) / \mathrm{PDC}(i)$

$\varphi_{3} \quad$ The added time of shipment due to route blocking caused by disruptions

Spe $\quad$ Mean speed of vehicles

$V c p t \quad$ Mean cost of vehicles per unit time of delay in queue

\section{Decision variables}

$\lambda_{r / i} \quad$ Vehicle incoming rate to production/reproduction centers

$W T_{r / i}^{t} \quad$ Amount of time elapsed as delay time in $\mathrm{RC}(r)$ or $\mathrm{PDC}(i)$

$N u m_{w r / i}^{t} \quad$ Total allocated vehicles connecting retailors to production/reproduction centers

\section{Appendix $\mathrm{C}$}

Features of small_size and large_size test problems $(t=$ $10)$ is shown in Table C.I.

Table C.I. Features of small-size and large-size test problems $(t=10)$.

\begin{tabular}{cccccccccccccccccccccc}
\hline & \multicolumn{11}{c}{ Small-size (S1-S10) } & \multicolumn{1}{c}{ Large-size (L1-L10) } \\
\cline { 2 - 3 } & 5 & 7 & 10 & 12 & 14 & 16 & 18 & 20 & 22 & 24 & 30 & 40 & 45 & 50 & 55 & 60 & 65 & 70 & 80 & 90 \\
$|\boldsymbol{h}|$ & 2 & 2 & 2 & 2 & 2 & 3 & 3 & 3 & 3 & 4 & 4 & 4 & 4 & 4 & 6 & 6 & 6 & 6 & 6 & 8 \\
$|\boldsymbol{i}|$ & 4 & 4 & 4 & 6 & 7 & 8 & 9 & 10 & 15 & 18 & 25 & 30 & 35 & 40 & 45 & 50 & 55 & 60 & 65 & 70 \\
$|\boldsymbol{r}|$ & 2 & 2 & 2 & 3 & 4 & 4 & 5 & 5 & 6 & 7 & 15 & 20 & 25 & 30 & 35 & 40 & 45 & 50 & 50 & 55 \\
$|\boldsymbol{w}|$ & 6 & 6 & 6 & 6 & 8 & 8 & 8 & 12 & 12 & 16 & 35 & 45 & 45 & 55 & 55 & 65 & 65 & 75 & 85 & 100 \\
$|\boldsymbol{p}|$ & 2 & 2 & 3 & 3 & 4 & 4 & 6 & 6 & 8 & 10 & 12 & 12 & 13 & 15 & 20 & 20 & 25 & 25 & 30 & 30 \\
$|\boldsymbol{v}|$ & 3 & 5 & 3 & 7 & 7 & 8 & 8 & 9 & 13 & 13 & 15 & 20 & 30 & 35 & 45 & 55 & 65 & 70 & 75 & 80 \\
\hline
\end{tabular}




\section{Biographies}

Soroush Aghamohammadi-Bosjin accomplished his MSc in Industrial Engineering at the Collage of Engineering, University of Tehran. He has published some articles in the area of scheduling, lot sizing, and closed-loop supply chain. His interests include supply chain management and optimization algorithms.

Masoud Rabbani is a Full Professor in the Industrial Engineering Department, University of Tehran, Tehran, Iran. His research interests are production planning, supply chain management, operations management, and Operations Research (OR).

Neda Manavizadeh accomplished her MSc in Industrial Engineering at the Collage of Engineering, University of Tehran in 2005. She also obtained her $\mathrm{PhD}$ in Industrial Engineering From the same college. Currently, she is an Assistant Professor in the Industrial Engineering Department of Khatam University, Tehran, Iran. Her research interests are production planning, MMAL, supply chain management, operations management, and Operations Research (OR). 